\title{
JOGOS DIGITAIS NA PROMOÇÃO DA SAÚDE: DESAFIOS E TENDÊNCIAS
}

\author{
Ana Isabel Veloso* \\ Liliana Costa* \\ Tânia Ribeiro***
}

\begin{abstract}
RESUMO
Na sociedade contemporânea, existem duas tendências que serviram de mote aos desafios expostos neste artigo: o envelhecimento populacional, que é uma realidade na sociedade atual em constantes mudanças econômicas, políticas e sociais; e o Acidente Vascular Cerebral (AVC), que representa um dos grandes problemas de saúde, afetando principalmente pessoas com mais de 55 anos. As plataformas digitais, concretamente os jogos digitais, podem ajudar: na promoção de uma vida ativa; na autonomia; e na reabilitação do idoso. Com o objetivo de fomentar essa ajuda foram concebidos e desenvolvidos dois jogos, JUMP e o PhysioFun, descritos no presente artigo. O jogo JUMP foi concebido e desenvolvido em participatory design com os alunos de uma Universidade de Terceira Idade. Este pretende promover a aprendizagem para o envelhecimento ativo, ajudar a sensibilizar para hábitos de vida saudáveis e eventualmente influenciar o jogador para mudar os seus comportamentos menos benéficos para outros mais saudáveis. O jogo PhysioFun foi concebido e desenvolvido numa metodologia de investigação de desenvolvimento com os profissionais de saúde e pretende servir como uma ferramenta completar à fisioterapia na reabilitação de pacientes vítimas de AVC. Para além disso, apresentam-se recomendações para o design de jogos para idosos e vítimas de AVC.
\end{abstract}

Palavras-chave: Jogos digitais. Idosos. Envelhecimento ativo. Reabilitação. Vítimas de AVC.

\section{ABSTRACT}

\section{DIGITAL GAMES IN HEALTH PROMOTION: CHALLENGES AND TRENDS}

The contemporary society has seen a growing trend towards two phenomena that have brought many challenges highlighted in this paper. One is the ageing of the population in today's society with current changes in economic, politics and social aspects. The other is one of the major health problems that has been mainly observed in people aged over 55 - Stroke. Digital platforms, particularly digital games, can encourage active ageing, enhance autonomy and contribute to the rehabilitation of older adults. Therefore, the games presented in this paper - JUMP and PhysioFun - aim to improve,

* Doutora em Ciências e Tecnologias da Comunicação pela Universidade de Aveiro, Portugal. Professora da Universidade de Aveiro, Portugal. E-mail: aiv@ua.pt

** Doutoranda em Informação e Comunicação em Plataformas Digitais pela Universidade de Aveiro, Portugal. Bolsista da Fundação para a Ciência e Tecnologia. E-mail: lilianavale@ua.pt

*** Doutoranda em Informação e Comunicação em Plataformas Digitais pela Universidade de Aveiro. Mestre em Comunicação Multimídia pela Universidade de Aveiro, Portugal. E-mail: ribeirotania@ua.pt 
assist and rehabilitate this target group. The game JUMP was designed in participatory design with a group of participants of a Portuguese University of Third Age. This game aims to encourage learning for active ageing and healthy lifestyle habits and eventually influence the player to change their behaviours to healthier ones. The game PhysioFun was designed with health professionals and aims to be complement physical therapy in terms of rehabilitation of stroke victims. Furthermore, this paper presents recommendations for designing games for older adults and stroke victims.

Keywords: Digital games. Older adults. Active ageing. Rehabilitation. AVC.

\section{RESUMEN}

\section{LOS JUEGOS DIGITALES EM LA PROMOCIÓN DE LA SALUD: RETOS Y TENDENCIAS}

En la sociedad contemporánea, hay dos tendencias que sirvieron como el tema de los retos que se presentan en este artículo. envejecimiento de la población es una realidad en la sociedad de hoy en día en los cambios económicos, políticos y sociales constantes. $\mathrm{Y}$ accidente cerebrovascular (ACV), que es uno de los principales problemas de salud, que afecta principalmente a personas mayores de 55 años. Las plataformas digitales, particularmente los juegos digitales pueden ayudar: la promoción de una vida activa; autonomía; y la rehabilitación de las personas mayores. Con el fin de promover esta ayuda fue diseñado y desarrollado dos juegos, JUMP y PhysioFun, que se describen en este artículo. El juego JUMP fue diseñado y desarrollado en el diseño participativo con los estudiantes de la Universidad de la Tercera Edad. Esto tiene como objetivo promover el aprendizaje de envejecimiento activo, ayudar a crear conciencia de los hábitos de vida saludables $\mathrm{y}$, finalmente, influyen en el reproductor para cambiar su comportamiento menos beneficioso para otros más saludables. El juego PhysioFun fue diseñado y desarrollado en un desarrollo de la metodología de investigación con profesionales de la salud y la intención de servir como una herramienta completa para la fisioterapia en la rehabilitación de pacientes víctimas d'accidente cerebrovascular. Por otro lado, el articulo presenta recomendaciones para el diseño del juego para las personas d' edad avanzada y víctimas de los accidentes cerebrovasculares.

Palabras claves: Videojuegos. Adultos mayores. Envejecimento active. Rehabilitación. El accidente cerebrovascular.

\section{Introdução}

Atualmente assiste-se a uma enorme crise demográfica. Segundo a Organização das Nações Unidas (2002), a população mundial envelhece a um ritmo acelerado, prevendo que o envelhecimento demográfico seja ainda mais agravado, nos países desenvolvidos, até 2050. Este fenómeno encontra-se associado a mudanças na sociedade, nomeadamente o aumento da esperança média de vida, a diminuição dos índices de mortalidade, a diminuição das taxas de natalidade e fecundidade, emancipação da mulher no trabalho, entre outros.
Se, por um lado, verifica-se um aumento da longevidade na população, por outro lado, o número de casos registrados de doenças crônicas, em especial os de Acidente Vascular Cerebral (AVC) também tem incrementado ao longo do tempo.

Na sociedade contemporânea, o AVC representa um dos problemas de saúde mais comuns, sendo a principal causa de morbilidade na União Europeia (UE); afeta especialmente indivíduos com mais de 55 anos, e traduz-se na doença que consome mais cuidados de saúde no seu tratamento (BRAININ 
et al, 2000). Com o envelhecimento crescente da população, as projeções indicam que a incidência ${ }^{1}$ e a prevalência ${ }^{2}$ desta patologia venha a aumentar (TRUELSEN; EKMAN; BOYSEN, 2005).

Os jogos digitais podem constituir ferramentas excelentes para ajudar na aprendizagem de conceitos e na mudança de comportamentos (COSTA; VELOSO, 2016a), bem como no apoio terapêutico (GRIFFTHS; KUSS; ORTIZ DE GORTARI, 2013), pela incorporação de desafios, mecanismos de recompensa, simulação de atividades, entre outros elementos.

Neste artigo apresentam-se dois exemplos de jogos (JUMP e PhysioFun) que se baseiam nas tendências atuais da sociedade e nos seus desafios, o envelhecimento da população e a reabilitação de vítimas de AVC. Apresenta-se o conceito de envelhecimento ativo, introduz-se alguns exemplos de jogos destinados aos idosos e expõe-se recomendações para o game design decorrentes das características do processo de envelhecimento. O jogo JUMP foi concebido e desenvolvido de acordo com estas recomendações, com o objetivo ensinar os conceitos fundamentais subjacentes ao envelhecimento ativo. Analisa-se o enquadramento do AVC na sociedade, destacam-se alguns exemplos de jogos utilizados no auxílio da reabilitação de vítimas do AVC e apresentam-se recomendações para o game design que surgem como consequências das características das lesões dos indivíduos vítimas de AVC. Por último apresenta-se o jogo PhysioFun, concebido e desenvolvido de acordo com as recomendações traçadas, com o objetivo de ajudar a fisioterapia clássica na reabilitação de vítimas de AVC.

\section{0 envelhecimento ativo}

O conceito de "envelhecimento ativo" foi adotado pela Organização Mundial da Saúde (OMS) no final da década de 1990 e tem evoluído desde então, abrangendo não só a ideia de "envelhecimento saudável" diretamente relacionado com a saúde, mas incluindo também outras variáveis igualmente importantes que influenciam o envelhecimento. As

\footnotetext{
1 Incidência: número de casos novos numa determinada população durante um determinado período de tempo.

2 Prevalência: número total de casos existentes numa determinada população durante um determinado período de tempo.
}

variáveis determinantes para um envelhecimento ativo são: os serviços sociais e de saúde; os fatores comportamentais; os fatores pessoais; o ambiente físico; os fatores sociais; e os fatores econômicos. Todas estas variáveis estão interligadas com duas características transversais, o contexto cultural e o gênero (ORGANIZAÇÃO MUNDIAL DA SAÚ$\mathrm{DE}, 2002)$. Esta mudança de conceito significa que também é analisado o contexto de vida real do cidadão sênior, e este deixa de ser um cidadão passivo para se transformar num ser ativo, interveniente e participativo no seu envelhecimento. Os três pilares básicos deste conceito de envelhecimento ativo são a saúde, a segurança e a participação na sociedade (ORGANIZAÇÃO MUNDIAL DA SAÚDE, 2002).

Este estudo utilizará a definição proposta pela Organização Mundial da Saúde, que destaca que "Active ageing is the process of optimizing opportunities for health, participation and security in order to enhance the older adults quality of life as people age." (ORGANIZAÇÃO MUNDIAL DA SAÚDE, 2002; p. 2).

\subsection{Os jogos digitais para um envelhecimento ativo}

Alguns jogos digitais que são considerados adequados para um envelhecimento ativo. Os critérios de seleção dos jogos digitais foram: (a) apresentar como público-alvo os idosos; (b) data de publicação igual ou posterior a 2006; e (c) o jogo ser suficientemente caraterizado em termos de objetivos, regras, tecnologias utilizadas, finalidade e resultados.

A análise dos jogos foi realizada de acordo com os seguintes parâmetros: (a) o tipo e o objetivo do jogo; (b) as metas de jogo; (c) as regras; (d) as tecnologias utilizadas; (e) o contexto do jogador; e (f) feedback apresentado. Estes parâmetros são os principais elementos formais que definem um jogo digital: objetivos, feedback ou resultado ou mecanismos de recompensa e um conjunto de regras (SALEN; ZIMMERMAN, 2004). Além disso, as tecnologias utilizadas, o contexto do jogador e $\mathrm{o}$ tipo de jogo foram outros critérios utilizados a fim de compreender as decisões tomadas sobre design de interação. Seguem-se os jogos selecionados. 
Tai Chi (jogo digital) - é um jogo baseado em gestos com o proposito de permitir que as pessoas mais velhas pratiquem Tai Chi em sua casa (MORAIS; WICKSTORM, 2011). Para jogar este jogo, os idosos têm que imitar os movimentos realizados pelo instrutor, utilizando uma pulseira com sensor sem fios. Este sistema de telerreabilitação ocorre em tempo real e a interação ocorre quer no espaço físico, quer no espaço digital.

Jogo de mesa para Idosos - é um jogo de mesa com realidade aumentada que tem como objetivo "proporcionar lazer e diversão" (AL MAHMUD et al, 2010, p. 1). Para jogar este jogo, cada jogador tem que movimentar as peças no tabuleiro de jogo projetado de acordo com os quadrados indicados num cartão desenhado e assim encontrar o caminho para os monumentos indicados no mapa da cidade. No entanto, o jogador não pode avançar se um rei, rainha ou valete aparecerem no cartão desenhado. A equipe que chegar primeiro ao monumento final ganha o jogo. Este jogo-realidade mista é para múltiplos jogadores (4 jogadores divididos em duas equipes).

Walk2Win - é um jogo para plataformas móveis e tem como objetivo incentivar os adultos mais velhos "para se envolverem socialmente e fazer com que o tempo passado no centro da comunidade seja mais agradável" (MUBIN; SHAHID; AL MAHMUD, 2008, p. 1). O principal objetivo é combinar todos os pares de cartões associados com os hotspots da rede wireless. Para isso, os jogadores aproximam-se de cada hotspot e ativam-no movendo o dispositivo móvel sobre ele e viram os cartões para ver se correspondem. A interação é em tempo real, simultaneamente, utilizando os espaços físicos e digitais.

Dr. Kawashima body and brain exercises - é um jogo baseado em gestos que visa treinar o cérebro com desafios mentais e, ao mesmo tempo, exercitar o corpo, jogando com controles de movimento. A tecnologia usada é o Kinect e o objetivo do jogo é aumentar o nível do quociente de inteligência (QI). A interação com o jogo pode ser individual ou em grupo, em frente à televisão, com ou sem a presença da família e amigos (MICROSOFT, 2011).

Games of gifts purchase - é um jogo de computador que tem como finalidade melhorar ou manter as funções executivas e treinar a capacidade de planeamento dos utilizadores (LOPEZ-MARTINEZ et al, 2011, p. 1). O principal objetivo é comprar presentes para um parente próximo imaginário, tendo em conta que: (a) um pré-determinado orçamento não deve ser ultrapassado; e (b) os critérios apresentados sobre as preferências do parente imaginário. Existem medalhas virtuais de ouro, prata ou bronze, conforme a recompensa do nível e o desempenho dos idosos.

Ikiiki-Pom - é um dispositivo eletromecânico com um jogo inserido que os autores definem do gênero Whack-a-mole. Este jogo tem como objetivo manter as capacidades cognitivas dos idosos. Os autores pretendem ainda incorporar testes para medir as mudanças nos tempos de reação, memória de curto prazo, atenção visual e o controle do movimento das mãos (OGOMORI et al, 2011, p. 2). O principal objetivo do jogo é pressionar o botão certo, quando a luz se acende, a partir de um conjunto de interruptores de pressão que estão visíveis no dispositivo. O contexto de jogo é individual.

Jogo da Malha - é um jogo baseado na interação gestual concebido para os idosos (VELOSO, 2014) que visa adaptar para o meio digital o jogo tradicional português "Malha". Para jogar o jogo, os idosos atiram um disco em direção a um pino com o objetivo de derrubá-lo e deixar a malha perto do pino. A interação ocorre nos espaços físicos e digitais, de forma síncrona.

Jogos da comunidade social online miOne miOne ${ }^{3}$ é uma comunidade social on-line principalmente dirigida a idosos (VELOSO, 2014). Para além dos serviços de comunicação e informação oferecidos (por exemplo, saúde e notícias), a comunidade on-line tem uma área de jogos. Alguns dos jogos disponíveis são: "Caça Palavra", "Jogo de Memória", "Sudoku" e o "Jogo 4 em Linha". Os objetivos destes jogos são, por um lado, providenciar uma maneira divertida de passar o tempo livre, e por outro lado, treinar a atenção, a memória e o raciocínio lógico dos idosos. Os jogos têm também o propósito de facilitar a comunicação entre os membros da comunidade. A interação é remota e pode ser síncrona ou assíncrona.

Jogo de vídeo de ambiente para vigilância da saúde - é um jogo de ambiente (ZAVALA-IBARRA; FAVELA, 2012), ou seja, um jogo que reforça e incorpora a interação física. O objetivo do jogo

3 Disponível em: $<$ http://www.mione.pt $>$. 
é "monitorizar os idosos, a fim de detectar sinais precoces de fragilidade" (ZAVALA-IBARRA; FAVELA, 2012 p. 27). O jogador joga com o controle remoto, que mede a sua força, com o propósito de controlar um pássaro que voa no céu, evitar os obstáculos (aviões) e recolher um conjunto de objetos aleatórios que vão surgindo. Apesar de ser um jogo single-player, a interação é planejada para uma tela de grandes dimensões (ex.: TV), para que os amigos e familiares possam acompanhar os idosos.

Mosquito invasion - é um jogo baseado em gestos que visa utilizar as affordances familiares de objetos do mundo físico (RICE et al, 2011) e, assim, tornar-se uma interface para as ações e as rotinas diárias dos idosos. Os jogadores são responsáveis por proteger um bebê virtual de um enxame de mosquitos, golpeando-os fisicamente com objetos do espaço físico. Além disso, o jogo oferece duas opções de jogar: single-player e multiplayer.

Virtual soccer - é um jogo baseado em gestos com a mesma finalidade (RICE et al, 2011) do Mosquito invasion. Para jogar o jogo, o jogador tem de manter uma bola física saltando no ar sem tocar o chão, tanto tempo quanto possível. Este jogo pode ser jogado no modo single-player ou multiplayer.

Silver promenade - é um jogo baseado em gestos (Wii) que permite que o idoso frágil possa executar três tarefas diferentes: a) realizar passeios em parques virtuais (Balance Board); b) abanar o Wii Remote para contar certos elementos que surgem no jogo; e c) apontar o Wii Remote para tentar apanhar itens do jogo. Assim, os jogadores apontam o controle Wii Remote para apanhar uma borboleta que se move na tela, agitam o Wii Remote para contar coelhos e depois continuam a sua caminhada virtual (GERLING; SCHULTE; MASUCH, 2011).

Jogo de memória para idosos - é um jogo de labirinto concebido para a plataforma de TV que visa apoiar os idosos no treino das suas capacidades cognitivas, dando prioridade ao fator de entretenimento (ZWARTUIS-PELGRIM; RUYTER, 2008). Os jogadores têm como objetivo encontrar a saída e acumular pontos ao completar os minijogos, e assim obter uma maior pontuação no ranking.

Eldergames - é o nome do projeto que desenvolveu um conjunto de jogos para uma mesa de realidade mista que visa manter as capacidades cognitivas dos idosos tão intactas quanto possível através de exercícios e prevenindo a ocorrência de disfunções cognitivas. Ao mesmo tempo, as pontuações obtidas nos jogos são utilizadas como ferramenta de diagnóstico para descrever o estado dos jogadores (GAMBERINI et al, 2009). Para esse efeito, o projeto Eldergames providencia uma variedade de minijogos para treinar a memória, o raciocínio, a atenção seletiva, a atenção dividida, entre outras capacidades. Os jogadores podem jogar em colaboração ou competição.

De um modo geral, verificou-se que a maioria dos investigadores que aborda os jogos digitais para idosos (MORAIS; WICKSTROM, 2011) defende que: (a) as interfaces dos jogos devem ser semelhantes aos cenários do espaço físico; (b) os jogos devem incentivar a colaboração entre os jogadores e reforçar as suas redes de comunicação; (c) as regras devem ser claras e simples; (d) os jogos digitais são muitas vezes utilizados com a finalidade de treinar capacidades cognitivas; (e) os desenvolvedores de jogos devem ter em conta o custo do equipamento e as limitações físicas dos jogadores; (f) o uso de recompensas imediatas deve ser reforçado; (g) a familiaridade e proximidade com o jogo deve ser fomentada através de elementos da interface (ex.: o uso de imagens para identificar o jogador); e (h) as interfaces baseadas em gestos são benéficas para integrar uma interação física e social.

\subsection{Os efeitos do envelhecimento no design de jogos digitais}

As perspectivas em relação ao envelhecimento também se modificaram ao longo do tempo. Hoje em dia, sabe-se que o envelhecimento não resulta apenas de fatores biológicos/fisiológicos, mas também de fatores psicossociais e socioeconômicos (COSTA, 2013; PAÚL; FONSECA, 2005; VELOSO, 2014).

Apesar do processo de envelhecimento estar fortemente ligado com as características individuais de cada um, há mudanças que ocorrem em nível biológico e psicossocial que são comuns e incontornáveis, como: (a) o declínio físico através da diminuição dos órgãos sensoriais e de funções do organismo; (b) perda da massa muscular e da densidade óssea; (c) fadiga; (d) transformações 
na aparência (perda do material proteico da pele, deterioração e enfraquecimento da estrutura capilar, alteração da estatura e curvatura do corpo); e (e) diminuição do tamanho da pupila, quantidade de luz que entra na retina e sensibilidade (redução da visão periférica, noturna e da diferenciação da cor) (PAÚL; FONSECA, 2005). De um modo geral, estas vulnerabilidades determinam a adequabilidade dos dispositivos tecnológicos relativamente à interação e ao conteúdo que é veiculado.

Algumas mudanças que apresentam grande influência na concepção e design de jogos digitais são:

- O endurecimento do cristalino, que gera dificuldades em focar pequenos objetos e causa "vista cansada" (FISK et al, 2009; PAÚL; FONSECA, 2005). Assim, os elementos de jogo deverão atender a uma dimensão mínima, balanceamento de cor e iluminação, ajustes da profundidade de campo em relação à câmara e posicionamento dos objetos ao centro em vez das laterais da tela;

- A acuidade auditiva também é afetada com o envelhecimento, tal como a capacidade de executar tarefas simultaneamente e a memória a curto prazo. Estas mudanças acabam por determinar a tipologia de jogo e os desafios a incluir, bem como a separação da música ambiente da voz em off e identificação das personagens (BARLET;
SPOHN, 2012; COSTA, 2013);

- O campo lexical e semântico é afetado pela idade, nomeadamente a partir dos 70 anos (HELFER; FREYMAN, 2008), pelo que as regras e a narrativa de jogo deverão atender a mudanças na linguagem adotada;

- A diminuição do número de células nervosas apresenta impactos diretos na redução de energia, força, rigidez nas articulações e dificuldades de movimento. Deste modo, os jogos digitais deverão ser ajustados à falta de precisão e ao incremento dos níveis de ansiedade perante a novidade por parte deste público-alvo (BARLET; SPOHN, 2012; COSTA, 2013).

Relativamente aos aspetos psicossociais, o cidadão sênior é, geralmente, apresentado como pertencente a um grupo socialmente isolado, desfasado da comunidade, pelo que o contato com sistemas interativos nos espaços domésticos e privados deve promover a sua integração na comunidade e a aproximação entre familiares e amigos. De fato, a estimulação intelectual e as relações sociais que sejam gratificantes podem exercer um benefício real no combate aos sintomas biológicos e psicológicos do envelhecimento (COSTA, 2013). A Tabela 1 apresenta uma síntese dos diferentes efeitos do envelhecimento e a sua influência no design de jogos digitais.

Tabela 1 - Síntese dos efeitos do envelhecimento e a sua influência no design de jogos digitais

\begin{tabular}{l|lll}
\hline \multicolumn{2}{l}{ Efeitos } & Descrição & Influência no design de jogos digitais \\
\hline & & $\begin{array}{l}\text { - Perda da memória a } \\
\text { curto prazo, longo } \\
\text { prazo e memória } \\
\text { implícita }\end{array}$ & $\begin{array}{l}\text { - Repetição de desafios ou tarefas e } \\
\text { invocação de conhecimento } \\
\text { apreendido anteriormente, de modo a } \\
\text { estimular a memória e aprendizagem; } \\
\text { - Design de espaços virtuais que } \\
\text { estimulem o reconhecimento de } \\
\text { objetos e a memória espacial }\end{array}$ \\
\hline \multirow{3}{*}{ Atenção } & $\begin{array}{l}\text {-Declínio da atenção } \\
\text { seletiva e dividida }\end{array}$ & $\begin{array}{l}\text { - Estímulo da capacidade de atenção } \\
\text { e de resolução de tarefas através dos } \\
\text { jogos }\end{array}$ \\
\hline & $\begin{array}{l}\text { - Dificuldade na } \\
\text { compreensão e } \\
\text { produção de discurso; } \\
\text { Linguagem } \\
\text { e raciocínio }\end{array}$ & $\begin{array}{l}\text { - Estímulo da leitura, compreensão e } \\
\text { soletração através da narrativa e } \\
\text { descrição dos elementos do cenário; } \\
\text { - Declínio na } \\
\text { capacidade numérica }\end{array}$ & $\begin{array}{l}\text { através de da capercícios de lógica e de } \\
\text { cálculo. }\end{array}$ \\
\hline
\end{tabular}




\begin{tabular}{|c|c|c|c|}
\hline \multirow{3}{*}{ 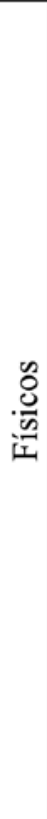 } & Visão & $\begin{array}{l}\text { - Dificuldade na } \\
\text { adaptação a diferenças } \\
\text { de iluminação e maior } \\
\text { sensibilidade ao } \\
\text { brilho; } \\
\text { - Redução da visão } \\
\text { periférica e de foco }\end{array}$ & $\begin{array}{l}\text { - Balanceamento dos níveis de brilho } \\
\text { e de cor dos cenários de jogo; } \\
\text { - Impor um tamanho mínimo para os } \\
\text { objetos de jogo; } \\
\text { - Ajuste do campo de visão da } \\
\text { câmara e da quantidade de luz nos } \\
\text { diferentes cenários (de modo a serem } \\
\text { consistentes). }\end{array}$ \\
\hline & Audição & $\begin{array}{l}\text { - Perda auditiva } \\
\text { periférica e } \\
\text { dificuldade em } \\
\text { perceber sons } \\
\text { distorcidos por ruído }\end{array}$ & $\begin{array}{l}\text { - Incorporação de legendas; } \\
\text { - Separação do ruído ambiente do } \\
\text { discurso da personagem; } \\
\text { - Identificação da fonte de som. }\end{array}$ \\
\hline & Tacto & $\begin{array}{l}\text { - Diminuição da } \\
\text { sensibilidade do tato, } \\
\text { vibração e } \\
\text { temperatura; } \\
\text { - Movimentos menos } \\
\text { precisos e mais lentos. }\end{array}$ & $\begin{array}{l}\text { - O factor velocidade/tempo não deve } \\
\text { condicionar a performance em jogo } \\
\text { nem ser elemento distintivo para } \\
\text { obter pontuação; } \\
\text { - Possibilidade de interagir com o } \\
\text { jogo através de vários comandos e } \\
\text { dispositivos. }\end{array}$ \\
\hline$\frac{n}{\frac{\pi}{0}}$ & $\begin{array}{l}\text { Suporte } \\
\text { social (em } \\
\text { alguns } \\
\text { casos) }\end{array}$ & $\begin{array}{l}\text { - Diminuição de } \\
\text { algumas redes de } \\
\text { amizade e de suporte } \\
\text { social }\end{array}$ & $\begin{array}{l}\text { - Promoção de relações sociais, da } \\
\text { sensação de comunidade e pertença } \\
\text { ao introduzir componentes sociais no } \\
\text { jogo. }\end{array}$ \\
\hline
\end{tabular}

Fonte: Adaptado de Costa (2013, p. 17-20).

Como se pode constatar pela análise da Tabela 1, são vários os efeitos do envelhecimento que um designer de videojogos deverá ter em conta de modo a tornar os jogos digitais acessíveis a um público mais vasto.

\section{A reabilitação física de doentes vítimas de AVC}

O Acidente Vascular Cerebral (AVC) é uma interrupção sanguínea na irrigação do cérebro devido a um bloqueio causado por um coágulo ou rompimento de um vaso sanguíneo. Estas anomalias provocam o corte de oxigénio e nutrientes, causando danos no tecido cerebral. A obstrução ou a hemorragia de uma artéria, quando envolve o hemisfério cerebral ou tronco cerebral, resulta num défice neurológico súbito e específico de acordo com as regiões do cérebro afetadas, o que significa que em cada vítima esta doença tem resultados clínicos diferentes (KLIJN; HANKEY, 2013).

Um AVC pode ser classificado em duas categorias: isquêmico e hemorrágico. $\mathrm{O}$ AVC isquêmico representa cerca de $87 \%$ da incidência dos episó- dios de AVC em todo o mundo (KLIJN; HANKEY, 2013) e caracteriza-se pelo bloqueio parcial ou total de um vaso sanguíneo. O AVC hemorrágico ocorre quando um vaso sanguíneo se rompe, causando uma hemorragia (SACCO et al, 2013). Ambas as categorias implicam uma série de constrangimentos e anomalias. No caso das deficiências motoras, estas caracterizam-se pela hemiplegia (paralisia completa), ou pela diminuição da força, hemiparesia, no lado oposto ao hemisfério cerebral lesado (WARD et al, 2006).

A incidência do AVC varia entre os diferentes países europeus, estimando-se entre 100 a 200 novos casos por cada 100 mil habitantes a cada ano, implicando uma enorme sobrecarga econômica (TRUELSEN; EKMAN; BOYSEN, 2005). O AVC constitui atualmente um dos problemas de saúde mais comuns e uma das principais causas de morbilidade e mortalidade em nível global (TRUELSEN; EKMAN; BOYSEN, 2005), ocorrendo predominantemente em indivíduos com idade superior a 55 anos (EPSTEIN; MASON; MANCA, 2008).

Uma das condições mais comuns pós-AVC é a espasticidade (AMERICAN STROKE ASSOCIA- 
TION, 2013). Trata-se de um distúrbio motor que faz com que os músculos se contraiam involuntariamente, alterando as propriedades musculares neurológicas como rigidez, fibrose e atrofia. Esta condição gera limitações e restrições que afetam o corpo, e, consequentemente, os pacientes em reabilitação enfrentam obstáculos profundos que atrapalham a execução de atividades diárias, participação social e tarefas, tanto individualmente como socialmente (BICKENBACH, 2012).

A recuperação de vítimas de AVC é feita por auxilio médico especializado, através de sessões de fisioterapia para uma recuperação efetiva da mobilidade (VEERBEEK et al, 2014). O paciente tem que reaprender os movimentos, o que depende de grandes volumes de prática motora de forma a promover a plasticidade neural, uma forma de reconexão cortical (AMERICAN STROKE ASSOCIATION, 2013). Segundo os dados disponíveis, para uma recuperação eficiente seria aconselhado cerca de 3.000 a 4.000 repetições de movimentos por sessão de fisioterapia. No entanto, a média atingida é de cerca de 32 repetições (KLEIM; BARBAY; NUDO, 1998). Para superar esta lacuna, médicos e fisioterapeutas recomendam atividades em contexto doméstico para o doente executar gestos com os membros afetados (KLEIM; BARBAY; NUDO, 1998; YONG JOO et al, 2010). Contudo, as atividades recomendadas nem sempre se revelam motivadoras, fato que, aliado à frustração causada pela falta de mobilidade e quadros depressivos, faz com que o doente não movimente os membros afetados pelo AVC, comprometendo a sua autonomia e atrapalhando a possibilidade de recuperação (HACKETT; ANDERSON; HOUSE, 2005; PORMEROY et al, 2011).

Existem atualmente diversas inciativas de investigação a fim de construírem soluções para apoiar a fisioterapia.

\subsection{Os jogos digitais na reabilitação física de doentes vítimas de AVC}

Os jogos digitais, como ferramenta de reabilitação ou terapia ocupacional, têm sido usados por diferentes grupos de indivíduos, desde crianças a idosos, pessoas com problemas físicos ou psicológicos e ainda por pessoas com deficiências intelectuais (O’NEIL; GATZIDIS; SWAIN, 2014).
Como experiência interativa, os jogos digitais são capazes de absorver os jogadores por grandes períodos de tempo, tirando o utilizador da sua realidade mais imediata, conseguindo distrair os jogadores de problemas como a dor física ou o mal-estar psicológico (CSIKSZENTMIHALYI, 2008). Para além disso, os jogos são ferramentas que permitem a exploração de desafios sem as consequências da vida real (SALEN; ZIMMERMAN, 2004).

$\mathrm{O}$ uso inicial de jogos digitais como mediadores terapêuticos para a recuperação do membro superior afetado pelo AVC está diretamente relacionado com os sistemas robóticos para a reabilitação em contexto hospitalar, que apesar de serem meios de recuperação eficientes, estão limitados às instituições de saúde, e ainda são uma tecnologia dispendiosa (JARRASSÉ et al, 2014).

Ainda que existam inúmeros jogos para reabilitação de diversas patologias, procuraram-se exemplos que cruzassem os interesses desta investigação. A pesquisa foi efetuada com as palavras "rehabilitation", "videogames" ou "games"; "AVC" e "sensor". Foram selecionadas as publicações cujos jogos foram pensados para o auxílio da terapia de indivíduos vítimas de AVC. A Tabela 2 apresenta uma síntese desses jogos identificados.

O jogo digital Recovery Rapids consiste na gamification de uma técnica de fisioterapia denominada Constraint Induced Movement Therapy (CI). Esta terapia obriga o uso do membro superior afetado o máximo possível, restringindo o uso do membro saudável. Este jogo está desenhado para 3 horas de reabilitação diária, durante 10 dias consecutivos. O paciente, como jogador, assume o papel de um remador de caiaque e é encorajado a evitar barreiras utilizando o controle gestual (MAUNG et al, 2014), sendo que o mapa do jogo pode ser personalizado pelo cuidador de saúde ou fisioterapeuta.

O jogo digital Rehabilitation Gaming System é semelhante ao jogo anterior. O objetivo do jogador é mimetizar o movimento que o avatar faz na tela. O jogo inclui tarefas como desenhar no espaço ou associar formas a cores. Para além da reabilitação física, o jogo promete recuperar dificuldades ligadas à fala ou à concentração (GRECHUTA et al, 2014). 
Tabela 2 - Síntese dos jogos utilizados no auxílio da terapia de indivíduos vítimas de AVC

\begin{tabular}{|c|c|c|c|c|c|}
\hline \multicolumn{2}{|c|}{ Jogo(s) } & Objetivos & Regras & $\begin{array}{l}\text { Contexto } \\
\text { do jogador }\end{array}$ & Tecnologia \\
\hline & $\begin{array}{l}\text { Recovery } \\
\text { Rapids }\end{array}$ & $\begin{array}{l}\text { - Evitar barreiras } \\
\text { recorrendo ao } \\
\text { controlo gestual }\end{array}$ & $\begin{array}{l}\text { - Evitar } \\
\text { barreiras e } \\
\text { apanhar } \\
\text { recursos que } \\
\text { caem de para } \\
\text { quedas }\end{array}$ & $\begin{array}{l}\text { - Remador } \\
\text { de um kayak }\end{array}$ & $\begin{array}{l}\text { - Computador } \\
\text { - Microsoft } \\
\text { Kinnect } \\
\text { - Luva com } \\
\text { sensores não } \\
\text { especificados }\end{array}$ \\
\hline & $\begin{array}{l}\text { Rehabilitation } \\
\text { Gaming } \\
\text { System }\end{array}$ & - Vários mini-jogos & $\begin{array}{l}\text { - Repetir } \\
\text { movimentos } \\
\text { executados por } \\
\text { um avatar na } \\
\text { cena de jogo }\end{array}$ & $\begin{array}{l}\text { - Primeira } \\
\text { pessoa: } \\
\text { visualização } \\
\text { do tronco e } \\
\text { membro } \\
\text { superiores. }\end{array}$ & $\begin{array}{l}\text { - Computador } \\
\text { - Microsoft } \\
\text { Kinnect } \\
\text { - Luva com } \\
\text { sensores não } \\
\text { especificados }\end{array}$ \\
\hline \multirow[t]{2}{*}{ 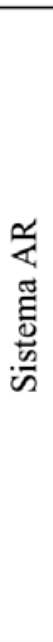 } & Brick'a'Break & $\begin{array}{l}\text { - No topo do } \\
\text { cenário de jogo } \\
\text { estão um conjunto } \\
\text { de tijolos. O } \\
\text { jogador deve rodar } \\
\text { uma bola virtual } \\
\text { recorrendo a um } \\
\text { paralelepípedo } \\
\text { físico de forma a } \\
\text { bola bater nos } \\
\text { tijolos de cima. }\end{array}$ & $\begin{array}{l}\text { - Acertar } \\
\text { sempre bola } \\
\text { com o } \\
\text { paralelepípedo } \\
\text { de forma a que } \\
\text { ela não vá para } \\
\text { fora de cena }\end{array}$ & \multirow[t]{2}{*}{$\begin{array}{l}\text { - Primeira } \\
\text { pessoa, há a } \\
\text { visualização } \\
\text { das mãos e } \\
\text { do antebraço } \\
\text { do jogador } \\
\text { na cena de } \\
\text { jogo. }\end{array}$} & \multirow[t]{2}{*}{$\begin{array}{l}\text { - Computador } \\
\text { - Web câmera }\end{array}$} \\
\hline & Shelf Stack & $\begin{array}{l}\text { - Colocar uma } \\
\text { chávena real no } \\
\text { topo de uma } \\
\text { prateleira virtual. }\end{array}$ & $\begin{array}{l}\text { - Colocar a } \\
\text { chávena no } \\
\text { sitio certo }\end{array}$ & & \\
\hline \multirow{2}{*}{ 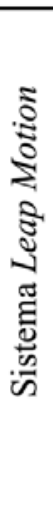 } & \multirow[b]{2}{*}{$\begin{array}{l}\text { Três mini } \\
\text { jogos sem } \\
\text { designação } \\
\text { comercial }\end{array}$} & $\begin{array}{l}\text { - Organização de } \\
\text { bolas com textura } \\
\text { de algodão }\end{array}$ & $\begin{array}{l}\text { - Mudar bolas } \\
\text { com textura de } \\
\text { algodão de um } \\
\text { recipiente para } \\
\text { o outro. }\end{array}$ & \multirow{2}{*}{$\begin{array}{l}\text { - Primeira } \\
\text { pessoa: } \\
\text { visualização } \\
\text { de uma } \\
\text { virtualizaçã } \\
\text { o da mão do } \\
\text { jogador. }\end{array}$} & \multirow[b]{2}{*}{$\begin{array}{l}\text { - Computador } \\
\text { - Leap Motion }\end{array}$} \\
\hline & & $\begin{array}{l}\text { - Empilhamento de } \\
\text { blocos }\end{array}$ & $\begin{array}{l}\text { - Empilhar } \\
\text { paralelepípedo } \\
\text { s virtuais uns } \\
\text { em cima dos } \\
\text { outros de } \\
\text { forma a fazer } \\
\text { torres }\end{array}$ & & \\
\hline
\end{tabular}

Fonte: Ribeiro (2016, p. 38-43).

Ambos os jogos anteriores utilizam o Kinect e uma luva para medirem diagonais funcionais e motricidade fina, respectivamente. Mesmo sendo boas alterativas para a recuperação de um membro superior em doentes vítimas de AVC, são muito dispendiosos.

O sistema com o sensor leap motion, capta as mãos do jogador, conseguindo medir a motricidade 
fina (CHARLES et al, 2014). Ainda que tenha um custo inferior aos anteriores, implica um esforço adicional por parte do utilizador para manter as mãos na área de detecção.

O Sistema Realidade Aumentada (RA) apresentado na Tabela 2 é uma solução de baixo custo e oferece a vantagem de fazer uso dos objetos reais. No entanto, o jogo Shelf Stack consiste numa virtualização de uma tarefa diária, desafio pouco apreciado pelos pacientes de AVC.

Para além dos jogos identificados e descritos, destaca-se o sistema Sword Health, que é uma interface vestível para doentes vítimas de AVC e não um jogo. O sistema monitoriza as posições do membro afetado e do tronco do paciente, de forma a fornecer feedback ao longo da recuperação do membro superior afetado em doentes vítimas de AVC. O feedback do tratamento pode ser consultado no smartphone, tablet ou computador. O paciente vítima de AVC que usa este sistema é convidado a exercitar movimentos de uma forma mecânica e repetitiva (SWORD HEALTH, 2016).

\subsection{Os efeitos das características de doentes vítimas de AVC no design de jogos digitais}

As taxas de prevalência e incidência do AVC aumentam exponencialmente com o aumento da idade (TRUELSEN; EKMAN; BOYSEN, 2005). Tendo em conta as faixas etárias de incidência do $\mathrm{AVC}$, estes indivíduos, para além dos problemas físicos e psicológicos inerentes ao processo de envelhecimento, enfrentam problemas de saúde graves que comprometem a sua autonomia e a execução de tarefas diárias.

Uma vítima de AVC depara-se com uma série de limitações e constrangimentos que afetam o sistema corporal físico, fisiológico e psicológico e a estrutura corporal nas suas dimensões anatômicas e psíquicas (BICKENBACH, 2012).

Um paciente vítima de AVC com hemiplegia ou hemiparesia numa primeira fase tenta sem sucesso usar os membros da parte afetada, mas falha nas primeiras tentativas. Esta limitação desencoraja e desmotiva o paciente, o que faz com que este recorra depois apenas à parte não afetada para realizar as suas tarefas, o que se torna um impedimento e retarda a sua recuperação (HACKETT; ANDERSON; HOUSE, 2005).

As repetições de movimentos, levadas a cabo pelos membros com dificuldades motoras, estimulam as áreas cerebrais não afetadas pela hemorragia. Estas áreas não afetadas, ao serem corretamente estimuladas, podem assumir as funções das áreas lesadas, de forma a compensar o dano (CRAMER, 2011). A repetição de movimentos ativa a plasticidade neural. Ou seja, a capacidade de o sistema nervoso responder a estimulações intrínsecas ou extrínsecas, cuja atividade compensa possíveis danos nas células nervosas. No caso de existir uma área anormal no cérebro, as áreas saudáveis adaptam-se de forma a compensar o dano (POMEROY et al, 2011). É de destacar que as consequências do AVC variam de pessoa para pessoa, consoante a área cerebral afetada, pelo que os efeitos não são iguais em todos os indivíduos, podendo existir funções cognitivas, físicas ou sociais intactas.

A compilação destes problemas de saúde em indivíduos vítimas de AVC, juntamente com os problemas decorrentes do processo de envelhecimento expostos na Tabela 1, permitiu-nos construir a Tabela 3 com a síntese dos efeitos do AVC e a sua influência no design de jogos digitais.

Tabela 3 - Síntese dos efeitos do AVC e a sua influência no design de jogos digitais

\begin{tabular}{l|lll}
\hline \multicolumn{1}{|c}{ Efeitos } & Descrição & Influência no design de jogos digitais \\
\hline & & - Dificuldade de & - Ambientes de jogo com objetos \\
& orientação; & simples e minimalistas com funções \\
& - Funções intelectuais; & claras e inequívocas; \\
Consciência & - Funções cognitivas de & - Objetivos de jogo claros e \\
& alto nível: tomada de & específicos; \\
& decisão, pensamento & - Feedback visual e sonoro; \\
& abstrato, planeamento & \\
de tarefas; &
\end{tabular}




\begin{tabular}{|c|c|c|c|}
\hline & Atenção & $\begin{array}{l}\text { - Declínio da atenção } \\
\text { seletiva e dividida: } \\
\text { perda de capacidade em } \\
\text { focar estímulos durante } \\
\text { o período de tempo } \\
\text { necessário para } \\
\text { posterior recordação. }\end{array}$ & $\begin{array}{l}\text { - Estímulo da capacidade de atenção } \\
\text { e de resolução de tarefas através dos } \\
\text { jogos, providenciando mais tempo } \\
\text { para a execução de ações e } \\
\text { compreensão e providenciar } \\
\text { feedback de todas as ações; }\end{array}$ \\
\hline & Linguagem & $\begin{array}{l}\text { - Problemas produção } \\
\text { de fala; } \\
\text { - Perda de funções } \\
\text { mentais específicas } \\
\text { como reconhecer e usar } \\
\text { sinais, símbolos e } \\
\text { outros componentes de } \\
\text { um idioma. }\end{array}$ & $\begin{array}{l}\text { - Evitar input/output de dados por } \\
\text { voz; } \\
\text { - Estímulo da leitura, compreensão e } \\
\text { soletração através da narrativa e } \\
\text { descrição dos elementos do cenário; }\end{array}$ \\
\hline & Audição & $\begin{array}{l}\text { - Dificuldades auditivas } \\
\text { nos extremos sonoros } \\
\text { da gama humana } \\
\text { audivel: pitches altos e } \\
\text { baixos. }\end{array}$ & $\begin{array}{l}\text { - incorporação de legendas; } \\
\text { - ajuste personalizado do som; } \\
\text { - apresentação clara dos feedbacks } \\
\text { sonoros; }\end{array}$ \\
\hline & Mobilidade & $\begin{array}{l}\text { - Redução do tónus } \\
\text { muscular; } \\
\text { - Resistência muscular; } \\
\text { - Dificuldade de } \\
\text { execução de } \\
\text { movimentos } \\
\text { complexos; } \\
\text { - Pouco controlo na } \\
\text { execução de } \\
\text { movimentos } \\
\text { voluntários; }\end{array}$ & $\begin{array}{l}\text { - A interface do jogo deve ser 3D } \\
\text { - Os exercícios a incluir numa fase } \\
\text { inicial devem ser simples, com pouca } \\
\text { amplitude de movimento; } \\
\text { - A amplitude e a diversidade de } \\
\text { movimentos deve ser gradualmente } \\
\text { inserida no jogo digital; } \\
\text { - Recompensar o jogador por } \\
\text { qualquer progresso na movimentação } \\
\text { do membro; }\end{array}$ \\
\hline & $\begin{array}{l}\text { Atividades } \\
\text { e } \\
\text { participação } \\
\text { social }\end{array}$ & $\begin{array}{l}\text { - Perda de autonomia na } \\
\text { execução de tarefas } \\
\text { diárias } \\
\text { - Mudanças de } \\
\text { temperamento e } \\
\text { personalidade }\end{array}$ & $\begin{array}{l}\text { - Promoção de relações sociais, com } \\
\text { o objetivo de promover a sensação } \\
\text { de comunidade e pertença ao } \\
\text { introduzir componentes sociais no } \\
\text { jogo. }\end{array}$ \\
\hline
\end{tabular}

Fonte: Adaptado de Ribeiro (2016, p. 18-22).

\section{Investigação empírica}

Nesta seção apresentam-se dois casos de desenvolvimento de jogos que se baseiam nas tendências atuais da sociedade e nos seus desafios - 0 envelhecimento da população e a reabilitação de vítimas de AVC

No caso do envelhecimento da população, é apresentado o projeto JUMP. O acrônimo JUMP4 surge a partir da missão do próprio projeto: Os

$4 \mathrm{O}$ jogo encontra-se em fase de desenvolvimento. Disponível em: $<$ http://www.jump.web.ua.pt $>$.
Jogos digitais e a avaliação da experiência de Utilização para Motivar um envelhecimento ativo e Promover hábitos saudáveis.

Trata-se de um jogo digital com o objetivo promover o envelhecimento ativo e hábitos de vida saudáveis, concebido em participatory design (SCHULER; NAMIOKA, 1993) com os idosos, considerando as áreas enquadradas no conceito de envelhecimento ativo proposto pela Organizaçao Mundial da Saúde (2002): Saúde, Segurança e Participação na Sociedade. 
No que concerne à reabilitação de vítimas de AVC, é apresentado do jogo PhysioFun, que foi concebido com uma narrativa adequada à recuperação dos movimentos de um estágio inicial da doença.

O jogo PhysioFun foi desenvolvido segundo uma metodologia de Investigação de Desenvolvimento (VAN DEN AKKER et al, 1999) seguindo as várias etapas metodológicas recomendadas: 1) investigação preliminar; design e desenvolvimento do artefato; 2) avaliação empírica; e 3 ) documentação, análise e reflexão.

\subsection{Proposta do jogo JUMP: jogo para um envelhecimento ativo}

O jogo JUMP é da tipologia RPG ("jogo de representação") em que o jogador encarna a personagem Sully, um pescador da cidade que está preso numa rotina e que o narrador Nubel força-o a viajar no tempo, de modo a recuperar valores e significado para a sua vida. A narrativa do jogo resume-se da seguinte forma: Sully, o pescador d'A Cidade, encontra-se cansado de ficar preso a uma rotina que nunca se habituou. Sem alento e refugiado no bar Baleia Selvagem, Sully tem que enfrentar o narrador Nubel, que o submete à experiência de uma máquina do tempo, de modo a que este possa recuperar valores e atribuir significado à sua própria vida.

O público-alvo deste jogo são alunos da Universidade Sênior, com idade superior a 50 anos. O desenvolvimento do conteúdo considerou o contexto e as motivações de 33 participantes de uma Universidade Sênior em relação aos seguintes tópicos: atividade física, nutrição, atividade cognitiva, segurança, participação na sociedade e utilização das tecnologias da informação e comunicação. A Figura 1 apresenta exemplos de materiais utilizados nas sessões (planos de atividades, flyers, questionários, card boards etc.).

Figura 1 - Exemplos de materiais utilizados nas sessões com alunos da Universidade Sênior

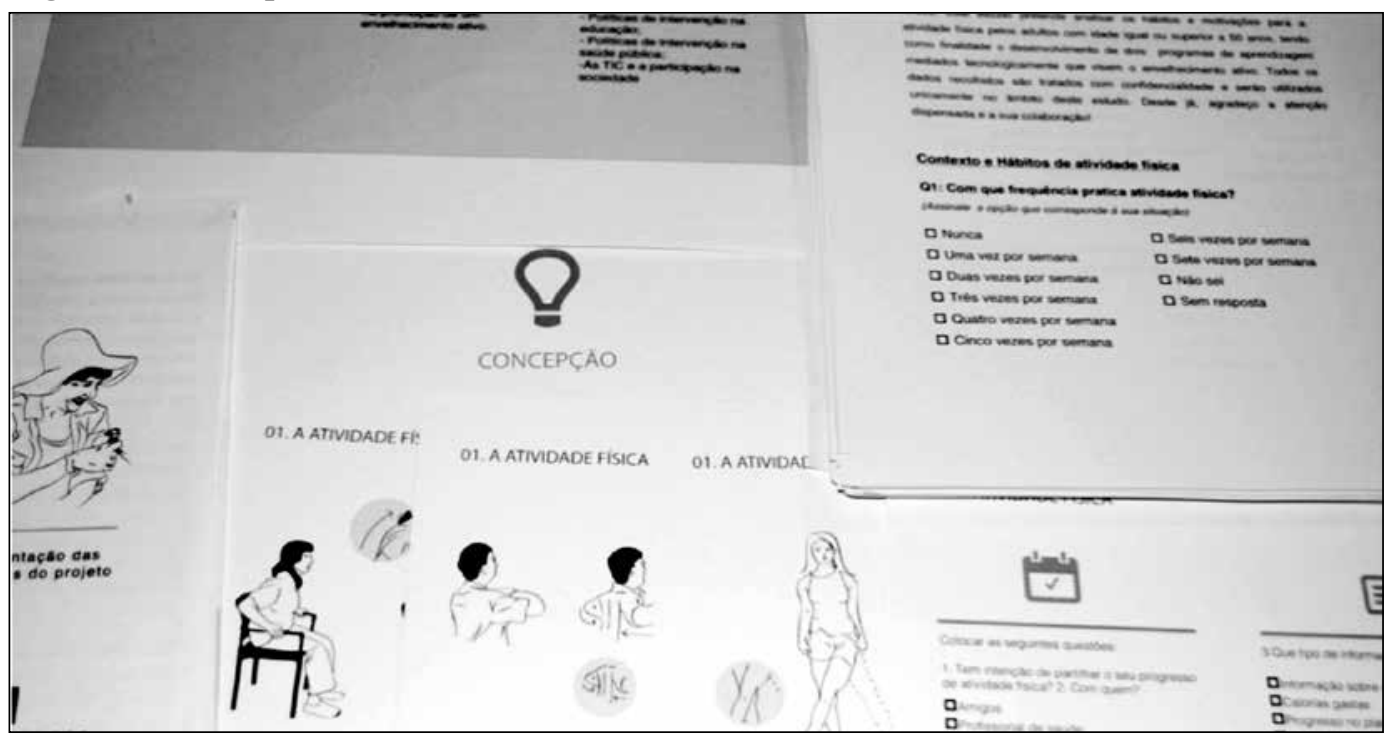

Fonte: Costa; Veloso (2016b).

A informação recolhida foi feita através de notas de campo, grupos de discussão e questionários. De um modo geral, os participantes, num programa de aprendizagem que promova um envelhecimento ativo, procuram: calendarizar atividades; partilhar o seu progresso; e encontrar simulações sobre os exercícios a praticar. Para além disso, manifestaram preferência em participar de eventos de discussão de ideias (ex.: tertúlias, mesa redonda); ver vídeos e resolver problemas relacionados com o conteúdo de aprendizagem; e debater o conteúdo de aprendizagem com amigos (COSTA; VELOSO, 2016a).

O levantamento do contexto do público-alvo permitiu estruturar o jogo em diferentes elementos que se encontram representados na base de dados (Figura 2). 
Figura 2 - Representação dos diferentes elementos de jogo na base de dados

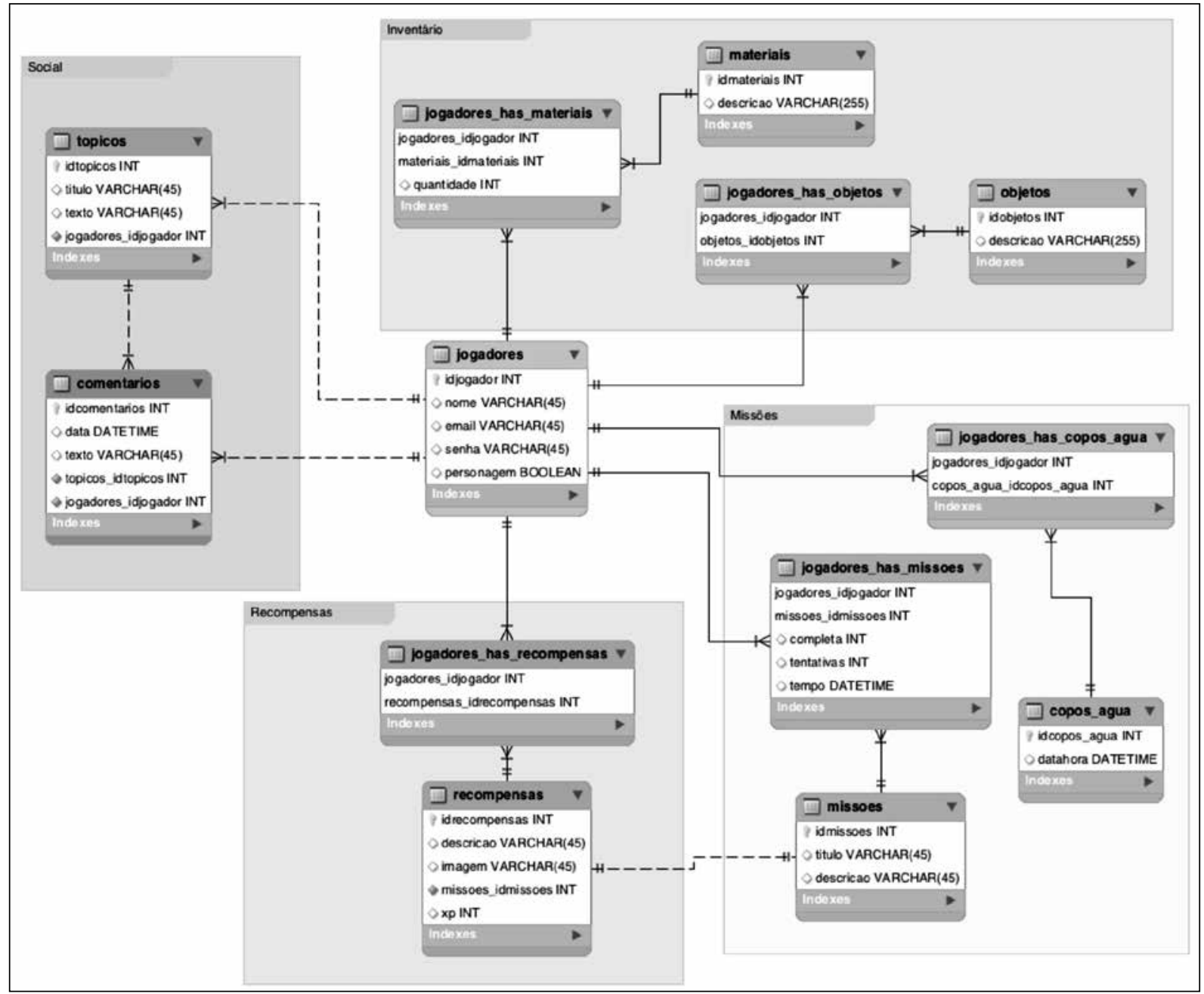

Fonte: Elaborado pelas autoras deste artigo.

Missões a cumprir: Estas missões podem ser relacionadas com o jogo ou com o espaço físico. As missões aparecem na tela de missões por ordem crescente em relação à data. A mascote da personagem (Jumpy) relembra a personagem principal (Sully) das missões em atraso. O jogador tem ainda que alimentar a energia do personagem ao beber até 8 copos de água no decorrer do jogo. Os tutoriais e as ajudas contextuais também simulam os exercícios a praticar.

Recompensas: O jogador é recompensado pelas suas missões através de pontos de experiência que são ordenados num ranking juntamente com os outros membros da comunidade.

Social (Espaço de convívio pós-experiência de jogo): $\mathrm{O}$ jogador pode interagir com outros membros da comunidade JUMP, partilhando as suas experiências e debatendo os conteúdos do jogo (Atividade física, Segurança e Participação na Sociedade).

Inventário: O jogador pode colecionar diferentes objetos e materiais que podem ser combinados para desbloquear peças-chave do jogo. Os objetos colecionados têm uma forte ligação com o desenrolar da narrativa e com o ambiente de jogo.

Destaca-se a seguir algumas das opções tomadas no design da interface e dos elementos de jogo JUMP. Estas opções são fruto de um conjunto de recomendações de design de interfaces que correspondem às necessidades e motivações do público-alvo presentes na literatura (COSTA, 2013; COSTA; VELOSO, 2016a; COSTA; VELOSO, 
2016b; FISK et al, 2009; IJSSELSTEIJN et al, 2007; PEARCE, 2008).

Optou-se pelo gênero de jogo - aventura gráfica - em que o jogador assume uma identidade de um personagem que tem que cumprir um conjunto de missões para avançar num jogo e na própria narrativa (RPG). Esta decisão levou em consideração, por um lado, que o fator empatia com um personagem pode alavancar mudança de comportamentos na transição das fases da pré-contemplação, contemplação, preparação, ação e manutenção no modelo de Prochaska e Diclemente (2005). Por outro lado, o fator de motivação que este público-alvo tem com os jogos de aventura e estratégia foi outro aspecto a levar em conta (COSTA; VELOSO, 2016b; PEARCE, 2008).

A narrativa encontra-se ligada a fatos históricos (ex.: Paris, 1948 - Declaração dos Direitos Humanos) (COSTA; VELOSO, 2016a), uma vez que se trata de uma das recomendações para o design de jogos digitais em relação a este público-alvo (COSTA; VELOSO, 2016b).

Relativamente aos desafios e comunicação no jogo, os desafios "jogador versus ambiente" foram priorizados relativamente a situações "jogador versus jogador". A comunicação é estabelecida off-game por causa de variáveis que podem afetar a experiência de jogo, como a dificuldade com multitarefa e a gestão do anonimato (CHRISTOU et al, 2013; COSTA; VELOSO, 2016b).

Em termos da escolha da plataforma, o jogo foi desenvolvido para a plataforma web, uma vez que o computador pessoal continua a ser o dispositivo mais utilizado pelo público dessa faixa etária (COSTA; VELOSO, 2016b).

O jogo incorpora também missões que integram desafios de memória, resolução de problemas e atenção. Estas capacidades cognitivas a serem estimuladas com o jogo correspondem às motivações deste público-alvo (COSTA; VELOSO, 2016b; NAP; DE KORT; IJSSELSTEIJN, 2009).

Por fim, alguns aspetos relacionados com a acessibilidade foram tidos em conta (ex.: evitar desafios que dependam muito da coordenação de movimentos ou tempos de reação; incorporar legendas; estabelecer um tamanho mínimo para os elementos de jogo) (COSTA, 2013; FISK et al, 2009).

\subsubsection{Personagens e cenários}

De modo a que o jogador conheça as personagens de jogo, as suas motivações e estabeleça uma relação de empatia, o jogo apresenta a sua biografia (Figura 3).

Figura 3 - Tela com a biografia de Sully (protagonista do jogo)

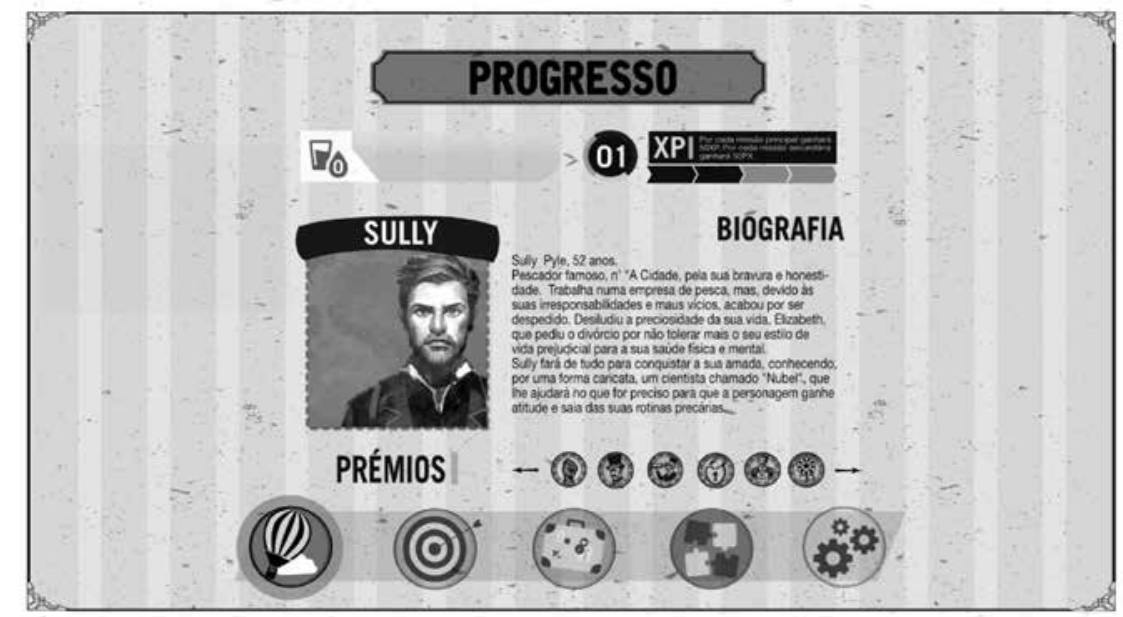

Fonte: Costa e Veloso (2016b).

As personagens foram concebidas tendo em conta os seguintes fatores: antropomorfismo (distinção entre figuras humanas e não humanas), androginia (distinção do gênero), credibilidade (semelhança com a realidade), homofilia (rever-se na aparência, motivações e ações da personagem) e atração pela personagem (CHEONG; JUNG; THENG, 2011; ISBISTER, 2006). As persona- 
gens do jogo resumem-se a: Sully - protagonista; Nubel - antagonista e o narrador do jogo; Jumpy - mascote; Barba Negra - charlatão na cidade; e Atlas - antagonista, narrador do jogo e proprietário da fábrica Lyton (Nubel disfarçado).

A identificação dos fatores apresentados foi importante para se conseguir a semelhança com a realidade, uma vez que se verificou preferência do público-alvo por elementos que se aproximam da realidade, comparativamente àqueles com algum nível de abstração/situações, ou seja, diferentes do mundo como se conhece (ex.: a ausência de gravidade, alterações de escala, entre outras).

Os cenários de jogo correspondem a:

- Londres, 1895: Neste cenário de jogo são introduzidas as missões relacionadas com a nutrição e participação na sociedade. Esta época foi escolhida com a finalidade de permitir ao jogador agir sobre algumas violações de direitos humanos básicos e situações de desnutrição. A combinação das missões de jogo com as missões a serem realizadas no espaço físico permitem estabelecer analogias entre as informações apresentadas em situação de jogo e as atividades do dia a dia. Este ano coincide também ao ano em que o romance de ficção científica A Máquina do Tempo foi lançado por H. G. Wells.

- Japão, Período Edo (1603-1868): Neste cenário de jogo, as missões estão relacionadas com a atividade física e cognitiva. Esta época foi escolhida com a finalidade de discutir a importância de controlar o corpo e a mente através da arte do samurai. A importância das atividades físicas e cognitivas também são exploradas com o livro Kaitai Shinsho, que contribuiu para a transformação da medicina japonesa e também com minijogos para treinar a percepção, atenção, memória e resolução de problemas.

- Paris, 1948: Neste cenário, as missões são relacionadas com a segurança e os direitos humanos que se encontram escondidos perto de Palais de Chaillot.

\subsubsection{Missões e sistemas de recompensa}

As missões são desafios pré-definidos com objetivos e recompensas. No jogo JUMP, estas seguem a estrutura de apresentação:

- da Narrativa através de cutscenes, em que é apresentado o enredo do jogo e que não há interação por parte do jogador (Figura 4);

- do objetivo de jogo de modo claro e direto (Frases orientadas à ação - verbos) (FONSECA; AMADO; COSTA, 2014);

- e quantificação da recompensa a obter com o cumprimento do objetivo (ex.: 50 pontos de experiência).

São exemplos de missões:

a) Obter medicamentos para superar a falta de

Figura 4 - Exemplo de um excerto de uma cutscene do jogo

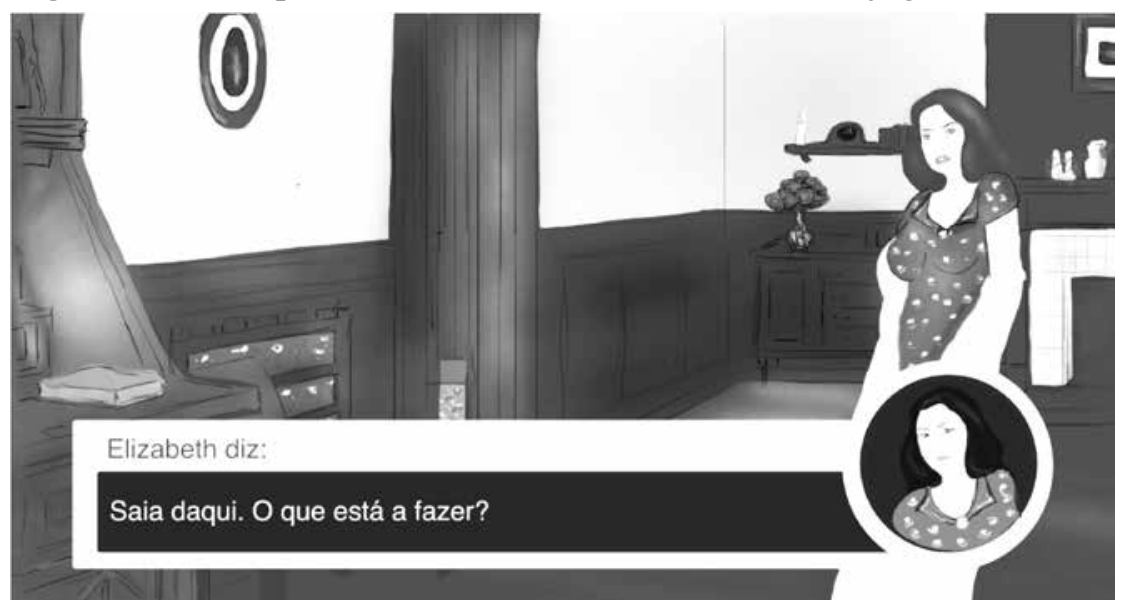

Fonte: Costa e Veloso (2016b). 
nutrientes (cenário Londres, 1895): Sully tem que conversar com Thomas Richard Allinson sobre as razões da desnutrição em crianças que trabalham numa fábrica, em pleno século XIX. Atrás do hospital encontra-se o charlatão Barba Negra. O objetivo principal do jogo é encontrar alimentos ricos numa determinada vitamina, de modo a produzir os melhores medicamentos para "ajudar na melhoria da visão e crescimento celular", "contribuir para o bom funcionamento do sistema nervoso, sangue, músculos e coração", "prevenir o aparecimento de cataratas e aliviar a vista cansada", "ajudar a aliviar a ansiedade e depressão", entre outros cenários. No final desta missão são fornecidas informações sobre macronutrientes e micronutrientes. Para além disso. as missões relacionadas com a nutrição associadas a comportamentos no espaço físico ficam também disponíveis na tela de missões secundárias.

b) Passar despercebido na fábrica do século XIX (cenário Londres, 1895): Sully tem que encontrar um uniforme para passar despercebido na fábrica. $\mathrm{O}$ uniforme encontra-se num contêiner misturado com outros contêineres falsos, em que se encontram bactérias que deram lugar a doenças mortais nessa época - tuberculose, cólera e tifo. O objetivo principal é lembrar-se onde se encontra o continer com o uniforme quando os diferentes contêineres são baralhados. No final desta missão o jogador recebe informação sobre as doenças mortais na atualidade e são desbloqueadas as missões relacionadas com atividades que promovam a saúde e a participação em planos de prevenção e políticas de saúde.

c) Jogo de sobrevivência (cenário Londres, 1895): Sully tem que escapar de Atlas, proprietário de uma fábrica que contratou crianças para preparar e fiar algodão (Figura 5). No final desta missão o jogador recebe informação sobre as condições de trabalho e do dia a dia no século XIX. São também desbloqueadas missões relacionadas com os objetivos do Millenium (UN MILLENIUM PROJECT, 2005), visando incrementar a participação do jogador em comunidades locais, nacionais e/ou internacionais.

d) Encontrar ameaças que podem afetar a Segurança Humana no jornal Le Figaro (cenário Paris, 1948): Sully compra Le Figaro enquanto Eleanor Roosevelt discursa em pleno palácio de Chaliot. Termos como dignidade, direitos e liberdade ecoam na cidade. Ao folhear o jornal, Sully tem que identificar um conjunto de ameaças que podem afetar a segurança humana. Missões relacionadas com a intervenção em diferentes tipos de ameaça humana verificadas no dia a dia são desbloqueadas na tela de missões.

As missões são atualizadas no menu onde estão listadas todas as missões do jogo (Figura 6).

Figura 5 - Jogo de sobrevivência

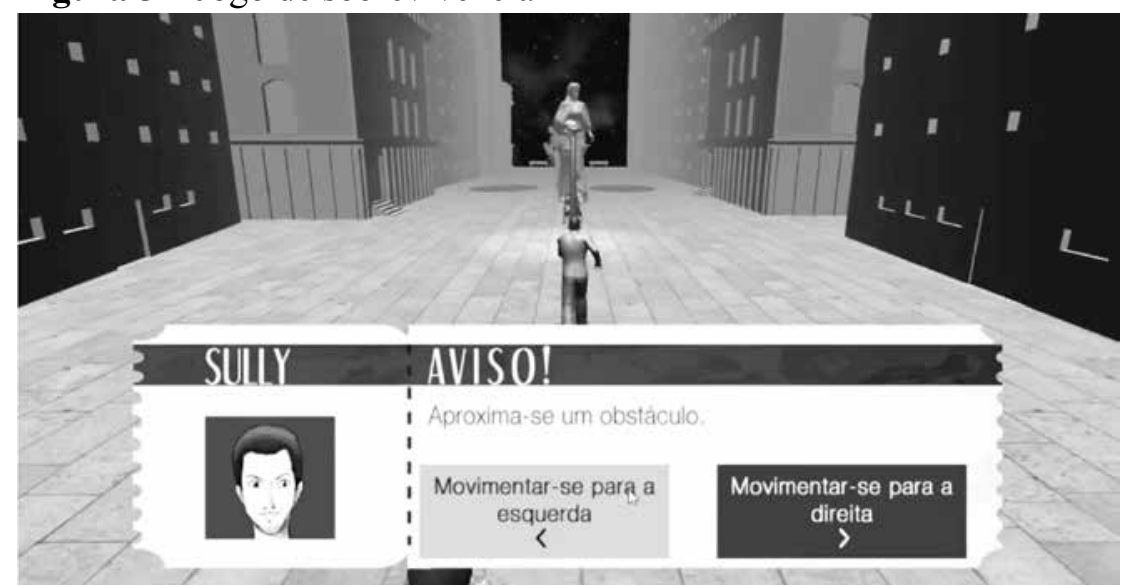

Fonte: Costa e Veloso (2016b). 
Figura 6 - Tela Missões

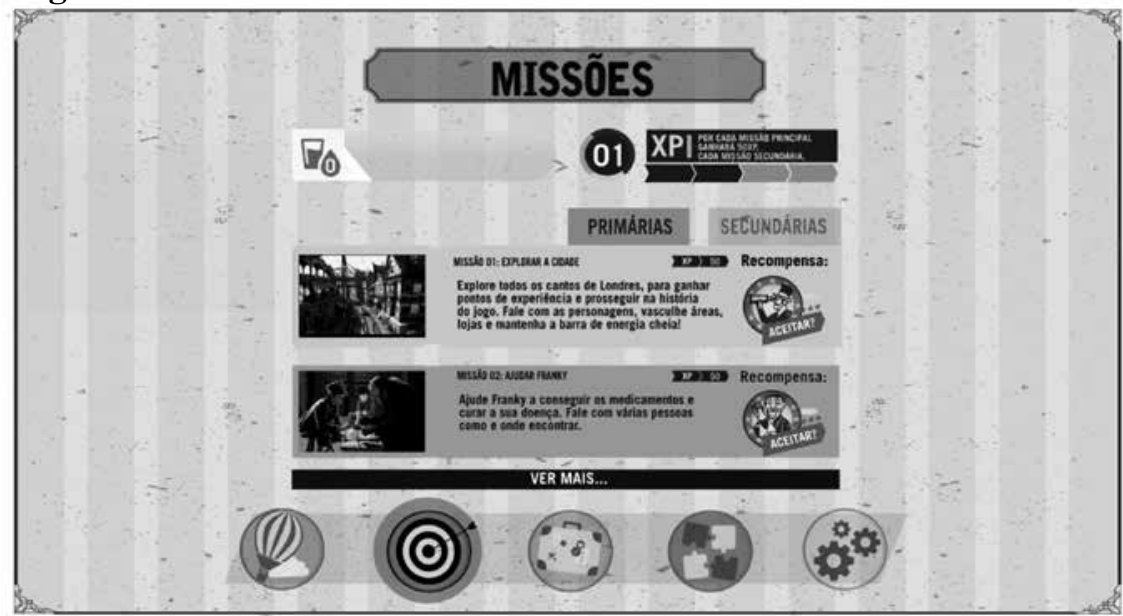

Fonte: Costa e Veloso (2016b).

Relativamente às recompensas, o jogador é recompensado na atividade de jogo, através de:

a) Pontos de experiência: Estes pontos traduzem o progresso do jogador em situação de jogo e encontram-se alinhados com os objetivos de jogo e comportamento do jogador. No jogo JUMP estes pontos são obtidos consoante o cumprimento das missões primárias (concretizadas no espaço digital) e missões secundárias (concretizadas no espaço físico). b) Pontos resgatáveis: Estes pontos são obtidos com a exploração do ambiente de jogo (tesouros, objetos e materiais).

c) Prêmios (badges): São atribuídos consoante a completude das missões.

É de realçar que o jogo JUMP não só encoraja o alcance das missões por parte do jogador (achievement), como também a própria exploração do ambiente de jogo. Deste modo, os jogadores podem colecionar jornais que apresentam informação sobre as missões, locais e fatos da própria história (Figura 7).

Figura 7 - Exemplo de objeto colecionável durante o jogo - jornal

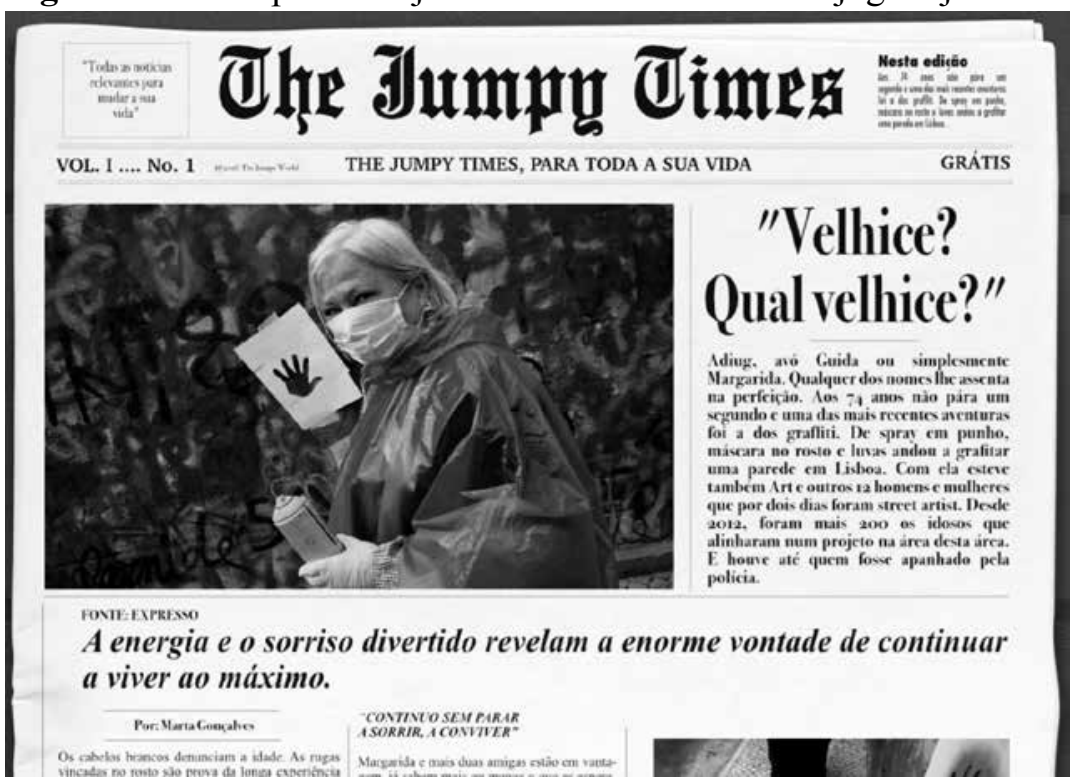

Fonte: Costa e Veloso (2016b). 
Esses objetos colecionáveis ajudam a estabelecer uma relação entre o espaço de jogo e o registro da própria experiência do jogador ("Estive aqui/I've been there") (DESURVIRE; CAPLAN; TOTH, 2004).
O inventário (Figura 8) contém duas categorias de elementos - objetos e materiais. Os materiais podem ser combinados de modo a gerar objetos e, assim, desbloquear a "Memória de Sully" (Figura 9).

Figura 8 - Inventário com objetos e materiais

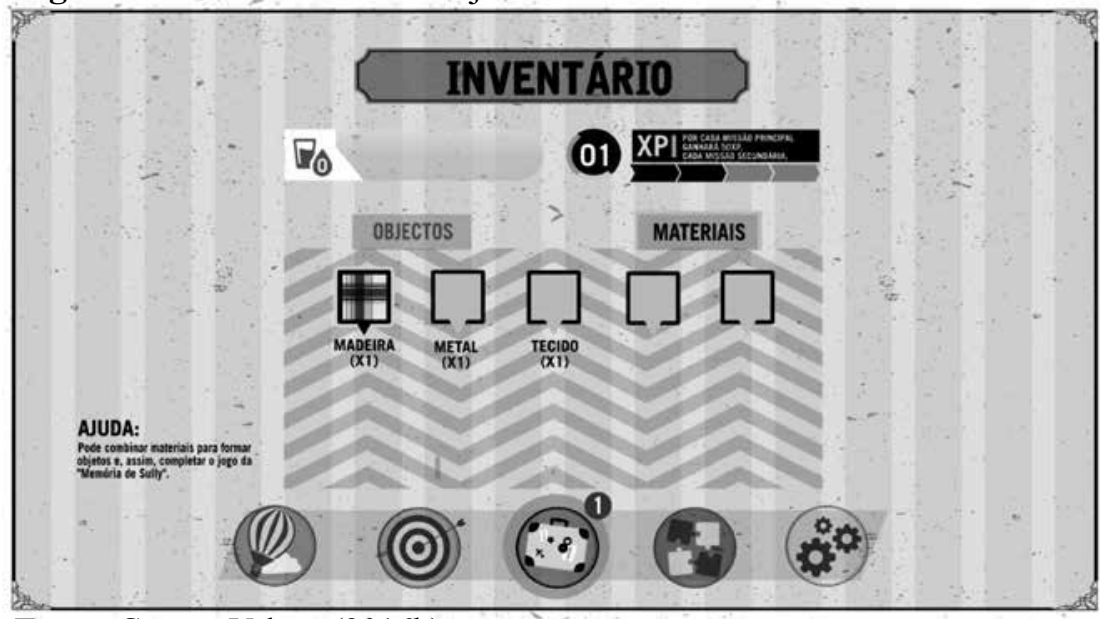

Fonte: Costa e Veloso (2016b).

Figura 9 - Jogo da memória

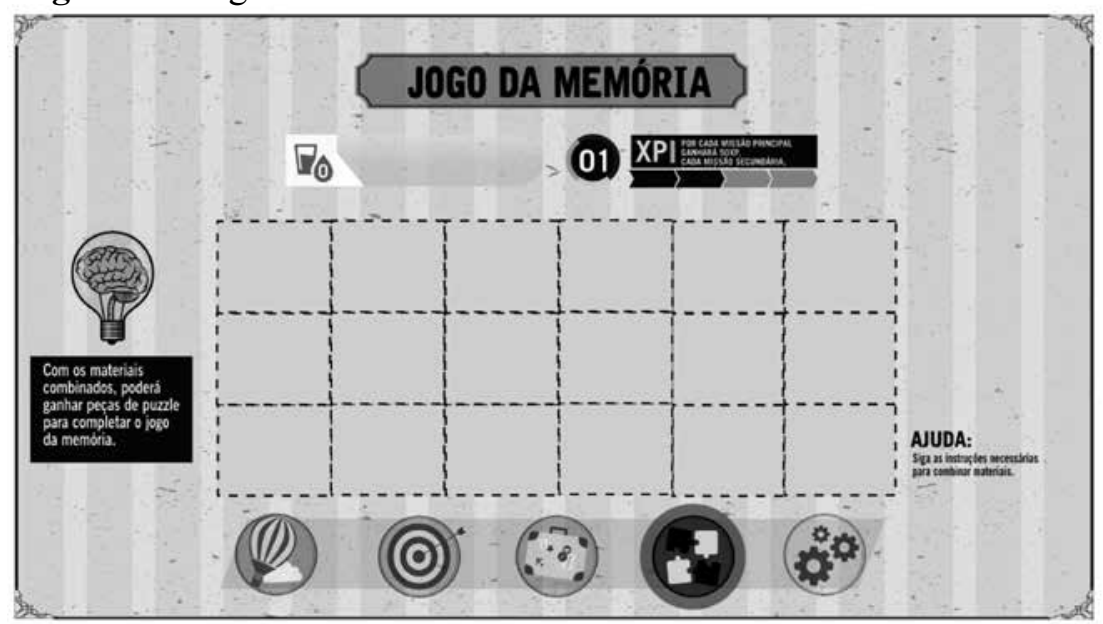

Fonte: Costa e Veloso (2016b).

Outro indicador de progresso de jogo é o registro de copos de água que o jogador já bebeu. Esta é uma das fontes de energia que alimentam Sully e, ao longo do jogo, surge o indicador de quantos copos de água o jogador precisa beber para evitar uma situação de game over.

\subsubsection{Mecanismos de ajuda ao jogador}

O jogo JUMP apresenta os seguintes mecanismos de ajuda ao jogador: a) tutorial embutido no jogo, onde o jogador é familiarizado com a navegação e controle da personagem, interação com 
objetos e aprendizagem de alguns indicadores de jogo (ex.: XP, monitorização dos copos de água e inventário); b) ajuda contextual quer através da interação com personagens não manipuláveis (NPC), quer através de informação que é apresentada na tela; c) Jumpy, que é um personagem que acompanha sempre o jogador e o relembra as regras, convenções de jogo e outro tipo de informação.

\subsubsection{A comunidade JUMP}

A comunidade JUMP é dinamizada na experiência de pós-jogo. Ou seja, os jogadores podem interagir na plataforma http://jump.web.ua.pt/ e partilhar as suas experiências em relação ao jogo e contribuir com informação, partilha de experiências e desafios relacionados com cada uma das variáveis do envelhecimento ativo: Saúde, Segurança e Participação na Sociedade.

O jogador tem ainda acesso a uma área de perfil onde é indicada a sua evolução em termos de experiência (XP), missões realizadas, missões por realizar e o seu progresso na comunidade JUMP (lugar no ranking).

\subsubsection{Ligação do jogo JUMP ao espaço físico}

O JUMP estabelece um paralelismo entre o espaço digital e o espaço físico, pelo que as ações ou tarefas do dia a dia do jogador influenciam a personagem e a sua prestação no jogo, através de missões secundárias. Algumas das missões relacionadas com o espaço físico são: a) Intervir em iniciativas de proteção do meio ambiente (limpeza de uma praia, proteção de uma floresta, plantação de árvores etc.); b) Partilhar uma receita típica do local/proximidade do local em que vive; c) Jogar "Dança Congelada" com amigos e familiares: a pessoa deve jogar este jogo acompanhada, escolhendo uma música. Quando tocar a música, todos dançam; quando a música parar, todos devem parar. $\mathrm{O}$ último a ficar quieto perde o jogo. Ganha quem conseguir ficar até o fim do jogo.

O cumprimento dessas mesmas ações traduz-se na evolução do jogador no espaço digital e obtenção de pontos de experiência (XP points).

\subsection{PhysioFun Game - jogo reabilitação de doentes vítimas de AVC}

O jogo PhysioFun é um jogo para ajudar complementarmente com fisioterapia clássica na reabilitação de doentes vítimas de AVC e reúne em si uma mistura de dois gêneros de jogo: Exergames e os Serious Games. Os Exergames são jogos que requerem a atividade física incorporada na mecânica de jogo e estão associados a uma tecnologia que rastreia esses movimentos. Os Serious Games são jogos que têm como objetivo fomentar a aprendizagem pela prática (RIBEIRO, 2016).

\subsubsection{Narrativa}

A conceção desse jogo incluiu determinados elementos que pretendem ajudar a potencializar a experiência de jogo ao nível da motivação, imersão, satisfação, flow ("experiência ótima") e aprendizagem.

Desse modo, planejou-se a narrativa com o propósito de motivar o jogador, tirando-o da sua realidade mais imediata, o que poderá ajudar na imersão na experiência ótima. $\mathrm{O}$ tema central da narrativa é a história da aviação, em particular as primeiras tentativas da humanidade "de colocar objetos no ar". A escolha da narrativa está articulada com as preferências do público-alvo, que são indivíduos com mais de 55 anos, uma vez que o AVC ocorre com mais frequência acima desta faixa etária (TRUELSEN; EKMAN; BOYSEN, 2005). Os idosos preferem jogos de aventuras, com resolução de problemas, em situações de player versus environment em vez de situações de player versus player (VELOSO; COSTA, 2016a).

Os níveis de jogo foram pensados para permitir uma aprendizagem progressiva e uma satisfação positiva nos resultados obtidos. Por isso, têm uma ordem crescente de complexidade na execução dos movimentos e uma complexidade crescente nos desafios. O jogo inicia com movimentos mais simples, de forma a serem introduzidos gradualmente movimentos mais complexos.

Os gestos incluídos no jogo resultam da análise de diversas entrevistas com profissionais da área (fisioterapeutas, investigadores, entre outros) para 
estabelecer uma base para os objetivos da terapia e especificar as necessidades dos doentes vítimas de AVC.

O jogo concebido está dividido em seis níveis baseados no levantamento de episódios históri- cos relevantes sobre os primórdios da aviação (GRANT, 2007). No primeiro nível de jogo, "O homem pássaro", a narrativa aborda as expectativas iniciais do voo, em que alguns seres humanos corajosos procuraram imitar os pássaros (Figura 10).

Figura 10 - O homem pássaro (nível 1) - rotação interna e externa do ombro

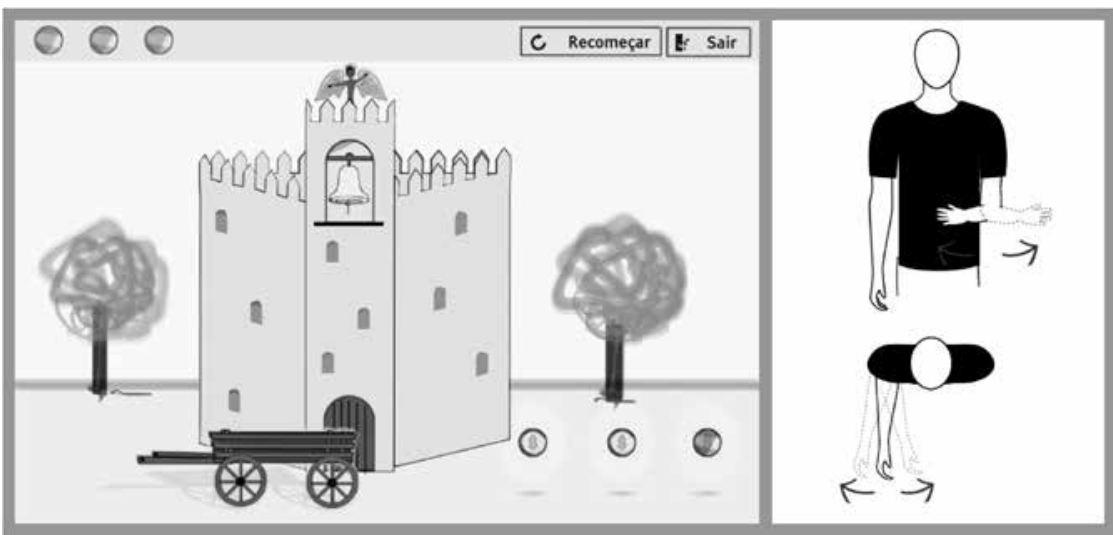

Fonte: Ribeiro, Veloso e Costa (2016).

O segundo nível baseia-se no episódio do Padre Bartolomeu Gusmão, quando apresenta à Corte
Portuguesa um objeto mais leve do que o ar - "A passarola" (Figura 11).

Figura 11 - A Passarola (nível 2) - flexão do cotovelo

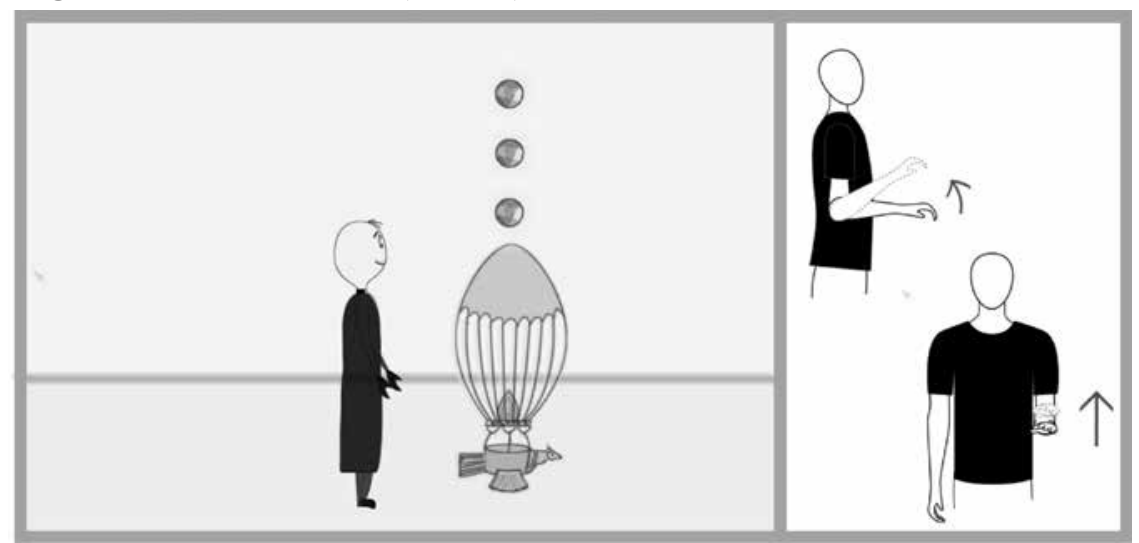

Fonte: Ribeiro, Veloso e Costa (2016).

O terceiro nível está relacionado com a primeira exibição pública de um balão de ar quente, efetuada pelos irmãos Montgolfier (Figura 12). 
Figura 12 - O balão (nível 3) - flexão do cotovelo com rotação externa do ombro

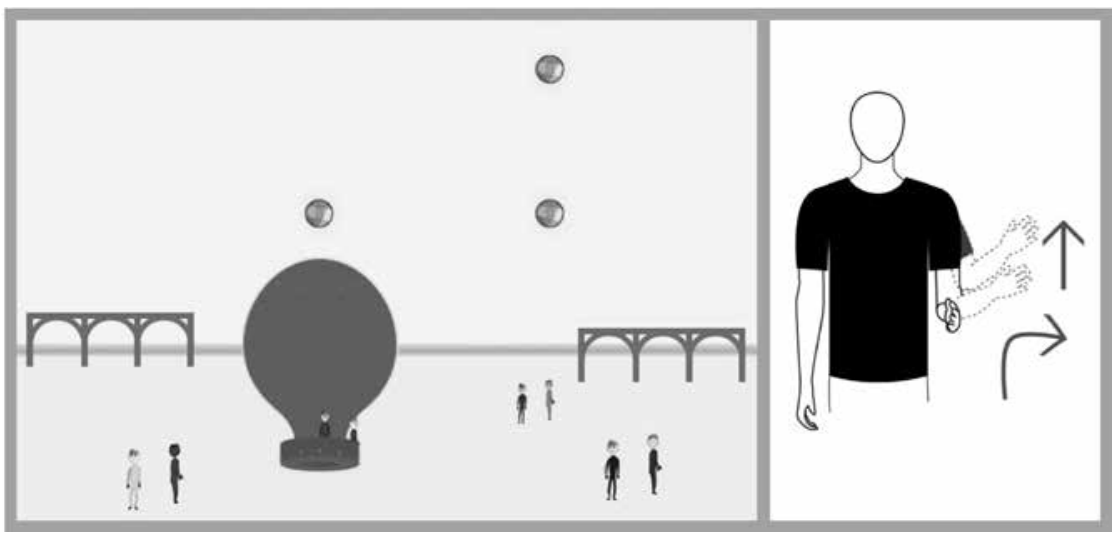

Fonte: Ribeiro, Veloso e Costa (2016).

O quarto nível está relacionado com os progressos científicos de ordem mecânica e assim aparece o motor (Figura 13);

este serve de mote para o quinto nível, o primeiro voo pilotado dos irmãos Wright (Figura 14).

Figura 13 - Preparar! (nível 4) - flexão do cotovelo com supinação do antebraço

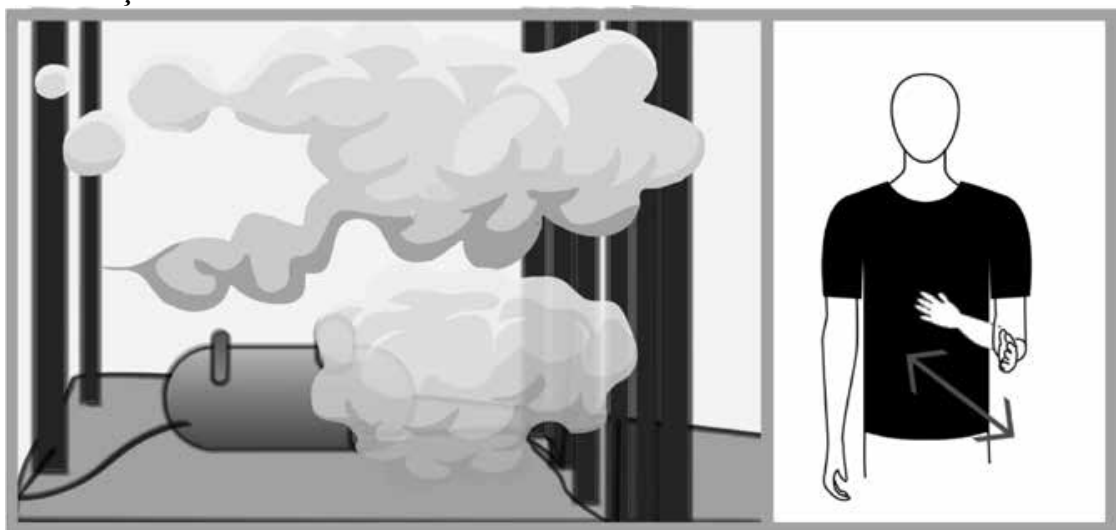

Fonte: Ribeiro, Veloso e Costa (2016).

Figura 14 - 12 segundos (nível 5) - flexão do ombro

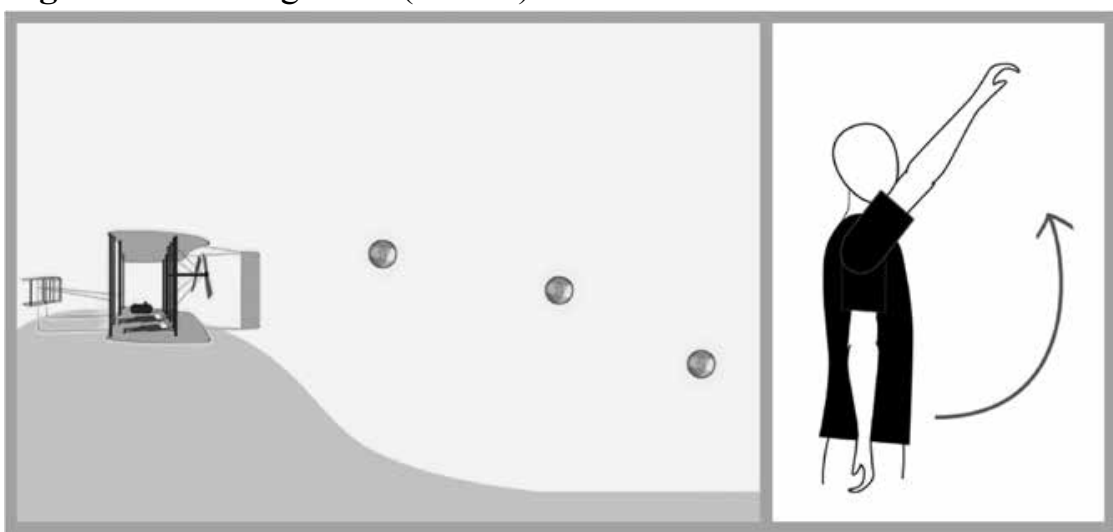

Fonte: Ribeiro, Veloso e Costa (2016). 
Esta fase do jogo termina no sexto nível com a primeira grande viagem da história, a travessia do canal da mancha, em 1909 por Louis Bleriot (Figura 15).

Figura 15 - Travessia do canal (nível 6) - flexão e abdução do ombro, com extensão do cotovelo

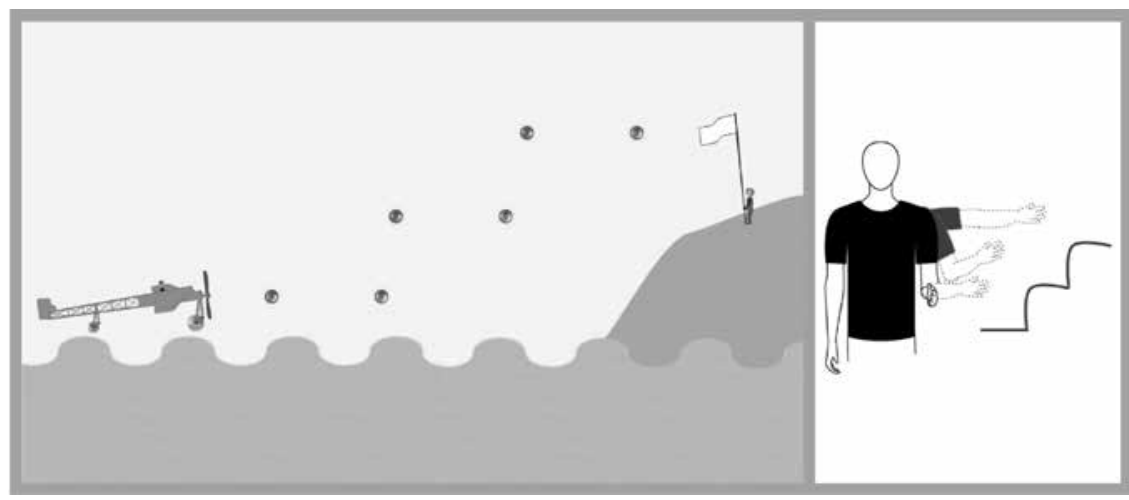

Fonte: Ribeiro, Veloso e Costa (2016).

O objetivo do nível 1 é posicionar a carroça embaixo da torre de forma que o homem que salta caia em cima dela (Figura 10). De modo a receber mais pontos, o jogador deve mover a carroça para que esta apanhe as moedas à direita do cenário. $\mathrm{O}$ movimento da carroça representa o movimento de rotação do jogador, fornecendo feedback visual.

Este primeiro nível funciona como um nível de habituação, onde é introduzido um desafio simples. O jogador deve executar uma rotação externa do braço para completar o nível com sucesso. O gesto presente no nível (movimentos de rotação interna e externa do ombro) foi pensado tendo em conta a posição adquirida pelos doentes com quadros de espasticidade, obrigando-os a mover o braço e tirando-o de junto ao peito.

No caso de ser um paciente num estágio mais avançado de recuperação, se executar a rotação interna e externa do ombro, consegue apanhar moedas, aumentando a sua pontuação. As moedas funcionam como bônus e o jogador não necessita obrigatoriamente apanhá-las. O nível é concluído com sucesso se o homem cair na carroça.

O objetivo do nível 2 é fazer com que a passarola suba (Figura 11). Para obter esse efeito é necessário que a chama arda, fazendo com que o ar dentro do balão fique mais leve do que o ar fora do balão. Para conseguir que a chama fique mais forte, o jogador deve abanar a mão como se estivesse dando ar a uma fogueira, fazendo um movimento de flexão do cotovelo. Os movimentos das mãos do Padre devem imitar os movimentos da mão do jogador, fornecendo feedback visual.

No primeiro nível do jogo, o jogador teve que realizar um movimento horizontal, agora já com o braço afastado do peito; no nível 2, o jogador deve realizar um movimento vertical. Para completar o nível do jogo com sucesso basta levantar o objeto do chão.

Tal como no nível anterior, as moedas funcionam como bônus e o jogador não necessita, obrigatoriamente, apanhá-las. O nível é concluído com sucesso se a passarola subir.

O objetivo do nível 3 é guiar o balão de forma a apanhar as moedas, evitando chocar com os pássaros, uma vez que eles provocarão danos no balão (Figura 12).

No primeiro e segundo níveis, o jogador não tem que apanhar todas as moedas, basta afastar a carroça e levantar a passarola do chão, respectivamente.

O terceiro nível do jogo é uma combinação dos movimentos dos dois jogos anteriores, e o jogador tem que realizar os movimentos de flexão do cotovelo e de rotação externa do ombro para fazer subir o balão, apanhar as moedas e evitar os pássaros.

O objetivo do nível 4 é melhorar a visibilidade do ambiente, afastando o fumo do motor (Figura 13). No nível 4 há uma mudança na mecânica de jogo, o movimento dos jogadores em vez de provocar uma translação de um objeto do jogo, deve 
fazer dispersar a fumaça que sai de um motor. $\mathrm{O}$ jogador realiza um movimento de flexão do cotovelo com supinação do antebraço, imitando assim o gesto que uma pessoa faz na vida real, na presença de fumaça. Quando o jogador movimenta a mão, há uma dispersão das partículas de fumaça. O jogo termina assim que o jogador conseguir dispersar fumaça, eliminando-a com o movimento.

O objetivo do nível 5 é manter o avião no ar quando este vai descer (Figura 14). No início há uma explicação sobre o contexto histórico - "Em 1903, os irmãos Wright, depois de algumas tentativas falhadas, realizaram com sucesso o primeiro voo com a duração de 12 segundos.”. Refere-se ainda que o avião é muito pesado e tem dificuldades para voar. O jogador, para jogar, deve levantar o braço a um nível superior ao ombro, efetuando o movimento de flexão do ombro. Quanto maior a velocidade de subida do pulso, maior a subida do avião. O jogador deve manter o avião no ar enquanto puder.

Tal como em níveis anteriores, as moedas funcionam como bônus, o jogador não necessita, obrigatoriamente, apanhá-las. O nível é concluído com sucesso quando o avião pousa.

O objetivo do nível 6 é fazer com que o avião chegue à costa, recolhendo as estrelas (Figura 15).
Este nível é baseado na história de Louis Bleriot, que realizou, em 1909, a primeira grande viagem da história da aviação - a travessia do Canal da Mancha.

Este último nível de jogo inclui os movimentos mais complexos, que resultam de uma junção dos movimentos anteriores, ou seja, o jogador tem que realizar em conjunto a flexão e a abdução do ombro, com extensão do cotovelo.

Para que o jogador complete este nível com sucesso o avião deve chegar à costa sem cair na água.

\subsubsection{Controlador de jogo}

O propósito principal do jogo é ajudar a devolver a mobilidade do membro superior afetado a doentes vítimas de AVC, recorrendo a gestos interativos para manipular os objetos no cenário de jogo. A interface a ser utilizada é baseada num input de três dimensões espaciais.

Ainda que existam atualmente no mercado soluções para capturar e guardar gestos humanos, como um dos propósitos desta investigação era também propor uma solução de baixo custo, optou-se por conceber uma pulseira (dispositivo wearable) (Figura 16) que serve de controlador do jogo.

Figura 16 - Primeiro protótipo da pulseira que controla o jogo

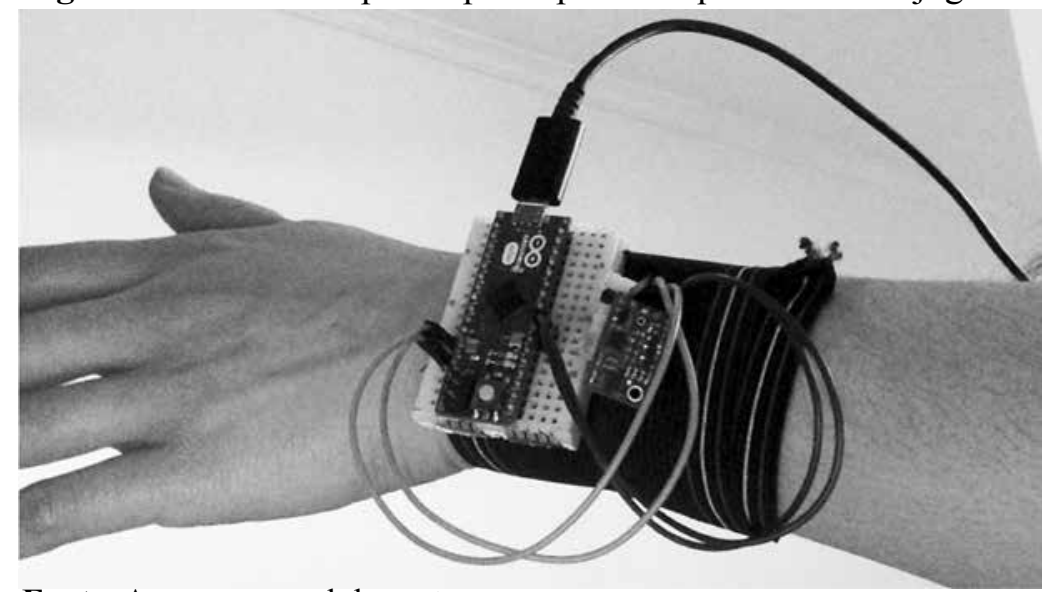

Fonte: Acervo pessoal das autoras.

Com o objetivo de tornar o controlador do jogo mais econômico para um consumidor final, foi desenvolvido um controlador específico recorrendo a um microcontrolador - um Arduino micro - e um Inercial Measurement Unit (IMU).
Um IMU é um dispositivo eletrônico de baixo custo que mede e registra a força angular e o campo magnético em torno de um determinado corpo, recorrendo a um acelerômetro, um giroscópio e um magnetômetro. Atualmente estes tipos de 
sensores são utilizados na indústria aeronáutica e massivamente em drones. Identificou-se ainda alguns projetos exploratórios que recorrem a esta tecnologia para medir dados biométricos, em particular para corrigir a postura de pacientes vítimas de AVC (DING, et al, 2008).

De acordo com as características de uma interface gestual (SAFFER, 2008), o sensor da interface é o IMU, o comparador é o Arduino e o atuador é o sistema de jogo. O Sistema composto pelo sensor e pelo atuador estão transformados no dispositivo wearable - a pulseira que deve estar no pulso do braço afetado pelo AVC. Sem esta pulseira, não é possível jogar o jogo.

\subsubsection{Protótipo digital}

Nessa fase inicial da investigação, e como prova de conceito, foi implementado o primeiro nível do jogo, bem como todo o sistema de navegação.

A interface do jogo deve ser simples, de fácil compreensão, recorrer a padrões de interação consistentes e ter em conta o contexto dos utilizadores. A estrutura de navegação adotada no Jogo PhysioFun tem quatro elementos:

- Menu principal: onde o utilizador acede ao menu de jogo, ao seu progresso e às opções de jogo (Figura 17);

- Jogar: onde o utilizador pode navegar pelos diferentes níveis de jogo, podendo eventualmente escolher um nível para jogar. Os níveis bloqueados aparecem com uma opacidade de $50 \%$ em relação aos níveis desbloqueados, sendo que um nível só é desbloqueado se o utilizador completar o nível procedente com sucesso;

- Progresso: onde é possível ter uma visão geral dos achievements conquistados;

- Opções: onde podem ser alterados parâmetros como volume do som, volume da música e resolução da tela.

Com o objetivo de comunicar informação textual nos menus, é necessário ter em consideração os formatos dos botões e a tipografia usada no texto. Para que não exista dúvida em relação à função de cada botão, existe, além da mensagem textual, um ícone que ilustra a função do mesmo.
A tipografia usada em todo o jogo é a fonte Tiresias, uma vez que é um tipo de letra com um bom compromisso entre a qualidade técnica e formal, sendo uma tipografia já testada em público sênior com dificuldades visuais (FONSECA; AMADO; COSTA, 2014).

Figura 17 - Menu principal

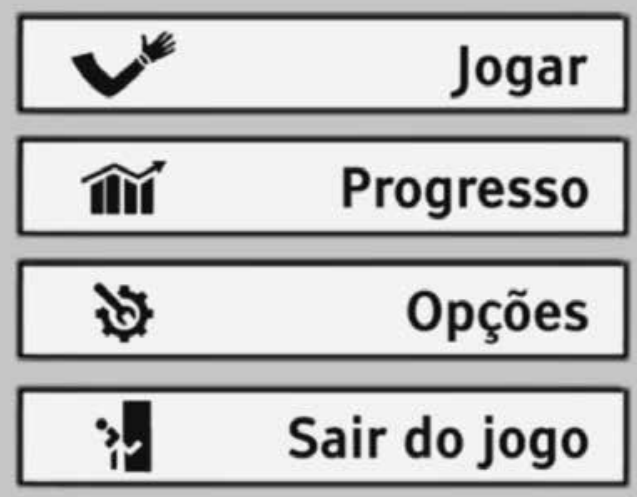

Fonte: Ribeiro, Veloso e Costa (2016).

\section{Considerações finais}

São vários os efeitos do envelhecimento que um designer de jogos digitais deverá ter em conta, de modo a tornar os jogos digitais acessíveis a um público mais vasto, mesmo considerando que o processo de envelhecimento é individual e que varia de pessoa para pessoa. O contexto do jogador acaba por ser o fator mais determinante quando se desenvolvem as componentes de um jogo. De fato, a análise do público para quem é destinado os artefatos permite perceber que um jogo digital deve ser pensado, desde a sua concepção, para quem se destina e ser adaptado a esse público, tendo em conta as características físicas e psicológicas do mesmo.

No contexto do envelhecimento ativo, é necessário fomentar cada uma das variáveis: Saúde, Segurança e Participação na sociedade, através do contexto de jogo. Além disso, recomenda-se que os jogos que têm o objetivo de incentivar o envelhecimento ativo, hábitos e novos comportamentos, como o jogo JUMP, tenham em conta os seguintes 
requisitos: avaliar as motivações intrínsecas do público-alvo; o design das missões deve enquadrar tanto o espaço físico quanto o espaço digital do jogador; o jogador deve ser premiado com pontos de experiência e as interações sociais devem ser fomentadas, com o objetivo de monitorar o progresso; a comunidade deve funcionar como um call to action ("chamada à ação"); a integração de avatares de modo a fortalecer a sensação de empatia entre o jogador e o avatar, que tem um propósito, uma missão e altera os seus hábitos com o decorrer do jogo; e incentivar a coleta de objetos significativos para a narrativa que podem ser associados ao esforço feito pelo jogador com a mudança de comportamentos.

As vítimas de AVC apresentam limitações profundas, desde limitações físicas visíveis a limitações cognitivas e intelectuais que comprometem os pacientes na execução de tarefas do quotidiano. O jogo digital PhysioFun Game apresenta-se como uma solução em contexto doméstico para o auxílio do tratamento de doentes vítimas de AVC, uma vez que, como já foi referido, as sessões de fisioterapia não se revelam suficientes para uma recuperação efetiva. Como recomendações de desenvolvimento de jogos para AVC, sugere-se que os jogos treinem movimentos como a rotação externa do braço, rota- ção interna e externa do ombro, flexão do cotovelo, entre outros que estimulem o movimento do braço e tire-o de junto ao peito. Estes jogos também devem mimetizar o movimento que o avatar faz na tela, espelhar situações da vida real, permitir o controle gestual e incorporar vários minijogos que testem diferentes movimentos.

\section{Agradecimentos}

Os autores agradecem aos especialistas do jogo JUMP que validaram o conteúdo para as sessões de design participativo - nas áreas de saúde, segurança e participação na sociedade; e aos fisioterapeutas que validaram a evolução do jogo PhysioFun.

Agradecemos aos alunos de Novas Tecnologias da Comunicação que desenvolveram o protótipo do jogo JUMP: André Pereira, Delymar Monteiro, José Reis e Mário Jader.

Agradecemos também à Universidade Sênior Gafanha da Nazaré pela participação e envolvimento nas sessões de design participativo.

Um parte da investigação relatada nesta publicação foi apoiada pela Fundação para a Ciência e Tecnologia (FCT) e do Fundo Social Europeu (FSE), sob Quadro Comunitário de Apoio III SFRH / BD / 101042/2014.

\section{REFERÊNCIAS}

AL MAHMUD, A. et. al. Designing social games for children and older adults: two related case studies. Entertainment Computing, v. 1, n. 3-4, p. 147-156, dez. 2010.

AMERICAN STROKE ASSOCIATION. Spasticity. 2013. Disponível em: <http://www.strokeassociation.org/ STROKEORG/LifeAfterStroke/RegainingIndependence/PhysicalChallenges/Spasticity_UCM_309770_Article. jsp>. Acesso em: 24 nov. 2015.

BARLET, M.; SPOHN, S. D. Includification - a practical guide to game accessibility. Vol. 14. Harpers Ferry, West Virginia: The Ablegamers Foundation, 2012.

BICKENBACH, J. E. ICF core sets. Toronto: Hogrefe Publishing, 2012.

BRAININ, M. et al. Acute neurological stroke care in Europe: results of the European Stroke Care Inventory. European Journal of Neurology, v. 7, n. 1, p. 5-10, 2000.

CHARLES, D. et al. Close range depth sensing cameras for virtual reality based hand rehabilitation. Wagon Lane, Inglaterra: Emerald Group Publishing Limited, 2014.

CHEONG, W. L.; JUNG, Y.; THENG, Y. L. Avatar: a virtual face for the elderly. In: INTERNATIONAL CONFERENCE ON VIRTUAL REALITY CONTINUUM AND ITS APPLICATIONS IN INDUSTRY, 10., 2011, New York. Anais... New York: ACM, 2011. p. 491-498

CHRISTOU, G. et al. Challenges of designing for sociability to enhance player experience in Massively Multi-player Online Role-playing Games. Behaviour \& Information Technology, v. 32, n. 7, p. 724-734, 2013. 
COSTA, L. V. Networked video games for older adults. 2013. 137f. Dissertação (Mestrado em Comunicação Multimédia) - Departamento de Comunicação e Arte, Universidade de Aveiro, Aveiro, Portugal, 2013.

COSTA, L. V.; VELOSO, A. I. Factors influencing the adoption of video games in late adulthood: a survey of older adult gamers. International Journal of Technology and Human Interaction, v. 12, n. 1, p. 35-48, $2016 \mathrm{a}$.

Game-based psychotherapy for active ageing: a game design proposal. In: INTERNATIONAL CONFERENCE ON TECHNOLOGY AND INNOVATION IN SPORTS, HEALTH AND WELLBEING, 1., 2016b, Vila Real. Anais... Vila Real, 2016b.

CRAMER, S. C. An overview of therapies to promote repair of the brain after stroke. Head \& Neck, v. 33, p. 5-7, 2011. Suplemento 1 .

CSIKSZENTMIHALYI, M. Flow: the psychology of optimal experience. New York: Harper Perennial Modern Classics, 2008.

DESURVIRE, H.; CAPLAN, M.; TOTH, J. A. Using heuristics to evaluate the playability of games. In: CHI EXTENDED ABSTRACTS ON HUMAN FACTORS IN COMPUTING SYSTEMS, 1., 2004, Viena. Anais... New York: ACM, p. 1509-1512.

DING, Z. Q. et al. Inertia sensor-based guidance system for upperlimb posture correction. Medical Engineering \& Physics, v. 35, n. 2, p. 269-76, 2008.

EPSTEIN, D.; MASON, A.; MANCA, A. The hospital costs of care for stroke in nine European countries. Health Economics, v. 17, p. 21-31, 2008. Suplemento 1.

FISK, A. et al. Designing for older adults: principles and creative human factors approaches. 2. ed. Cleveland: CRC Press, 2009.

FONSECA, I; AMADO, P.; COSTA, L. Desenho de interfaces para seniores: desafios e oportunidades no projeto SEDUCE. Revista Prisma, n. 23, p. 107- 138, 2014.

GAMBERINI, L. et al. Eldergames project: an innovative mixed reality table-top solution to preserve cognitive functions in elderly people. In: CONFERENCE HUMAN SYSTEM INTERACTIONS, 2., 2009, Catania. Anais... Catania: IEEE, 2009. p. 164-169.

GERLING, K. M.; SCHULTE, F. P.; MASUCH, M. Designing and evaluating digital games for frail elderly persons. In: INTERNATIONAL CONFERENCE ON ADVANCES IN COMPUTER ENTERTAINMENT TECHNOLOGY, 8., 2011, Lisboa. Anais... New York: ACM, 2011.

GRANT, R. Flight: 100 years of aviation. Great Britain: DK Publishing, 2007.

GRECHUTA, K. et al. Intensive language-action therapy in virtual reality for a rehabilitation gaming system. In: INTERNACIONAL CONFERENCE DISABILITY, VIRTUAL REALITY \& ASSOCIATED TECHNOLOGIES, 10., Gotemburgo, 2014. Anais... Gotemburgo: ICDVRAT, 2014. P. 265-273.

GRIFFTHS, M.; KUSS, D.; ORTIZ DE GORTARI, A. Videogames as therapy: a review of the medical and psychological literature. In: CRUZ-CUNHA, M. M.; MIRANDA, I. M.; GONÇALVES, P. Handbook of research on ICTs and management systems for improving efficiency in healthcare and social care. Hershey, USA: Medical Information Science Reference, 2013. P. 43-68.

HACKETT, M. L.; ANDERSON, C. S.; HOUSE, A. O. Management of depression after stroke: a systematic review of pharmacological therapies. Stroke: a Journal of Cerebral Circulation, v. 36, n. 5, p. 1098-103, 2005.

HELFER, K. S.; FREYMAN, R. L. Aging and speech-on-speech masking. Ear and Hearing, v. 29, n. 1, p. 87-98, jan. 2008.

IJSSELSTEIJN, W. et al. Digital game design for elderly users. In: CONFERENCE ON FUTURE PLAY, 1., 2007, Toronto. Anais... New York: ACM, 2007. P. 17-22.

ISBISTER, K. Better game characters by design: a psychological approach. San Francisco: Elsevier, 2006.

JARRASSÉ, N. et al. Robotic exoskeletons: a perspective for the rehabilitation of arm coordination in stroke patients. Frontiers in Human Neuroscience, v. 8, dez. 2014. Disponível em: <http://journal.frontiersin.org/article/10.3389/ fnhum.2014.00947/full>. Acesso em: 25 jul. 2016. 
KLEIM, J. A.; BARBAY, S.; NUDO, R. J. Functional reorganization of the rat motor cortex following motor skill learning. Journal of Neurophysiology, v. 80, n. 6, p. 3321-3325, 1998. Disponível em: <http://www.ncbi.nlm.nih. gov/pubmed/9862925>. Acesso em: 25 jul. 2016.

KLIJN, C. J.; HANKEY, G. J. Management of acute ischaemic stroke: new guidelines from the American Stroke Association and European Stroke Initiative. The Lancet Neurology, v. 2, n. 11, p. 698-701, 2003.

LOPEZ-MARTINEZ, A. et al. Game of gifts purchase: computer-based training of executive functions for the elderly. In: INTERNATIONAL CONFERENCE ON SERIOUS GAMES AND APPLICATIONS FOR HEALTH (SeGaH), 1., 2011, Braga, Portugal. Anais... Braga, Portugal: IEEE, 2011. p. 1-8.

MAUNG, D. et al. Development of recovery rapids - a game for cost effective stroke therapy. Foundations of Digital Games (FDG), 2014.

MICROSOFT. Dr. Kawashima body and exercises. 2011. Disponível em: $<$ http://marketplace.xbox.com/en-GB/ Product/Dr-Kawashimas-Body-and-Brain-Exercises/66acd000-77fe-1000-9115-d8024e4d0827>. Acesso em: 25 jul. 2016.

MORAIS, W.; WICKSTORM, N. A serious computer game to assist Tai Chi training for the elderly. In: INTERNATIONAL CONFERENCE ON SERIOUS GAMES AND APPLICATIONS FOR HEALTH (SeGaH), 1., 2011, Braga, Portugal. Anais... Braga, Portugal: IEEE, 2011.

MUBIN, O.; SHAHID, S.; AL MAHMUD, A. Walk 2 Win: Towards designing a mobile game for elderly's social engagement. In: BRITISH HCI GROUP ANNUAL CONFERENCE ON PEOPLE AND COMPUTERS: CULTURE, CREATIVITY, INTERACTION, 22., 2008, Inglaterra. Anais... Inglaterra: British Computer Society, 2008.

NAP, H.; DE KORT, Y.; IJSSELSTEIJN, W. A. Senior gamers: preferences, motivations and needs. Journal of Gerontechnology, v. 8, n. 4, p. 247-262, 2009.

OGOMORI, K. et. al. Requirements for a cognitive training for elderly or disabled people. In: INTERNATIONAL CONFERENCE ON BIOMETRICS AND KANSEI ENGINEERING (ICBAKE), 2011, Takamatsu, Japão. Anais... Takamatsu, Japão: Institute of Electronics, Information and Communication Engineers, 2011. p. 150-154.

O'NEIL, O.; GATZIDIS, C.; SWAIN, I. A state of the art survey in the use of video games for upper limb stroke rehabilitation. In: MA, M.; JAIN, L. C.; ANDERSON, P. (Ed.). Virtual, augmented reality and serious games for healthcare. Berlin: Springer, 2014. p. 345-370.

ORGANIZAÇÃO DAS NAÇÕES UNIDAS (ONU). Political Declaration and Madrid International Plan of Action on Ageing. Second World Assembly on Ageing, Madrid, Spain, 8-12 April 2002.

ORGANIZAÇÃO MUNDIAL DA SAÚDE. Active ageing - a policy framework. Second United Nations World Assembly on Ageing, Madrid, Spain, April 2002, p. 1-59.

PAÚL, C.; FONSECA, A. M. Envelhecer em Portugal. Lisboa: Climepsi, 2005.

PEARCE, C. The truth about bay boomer gamers: a study of over-forty computer game players. Journal Games and Culture, v. 3, n. 2, p. 142-174, 2008.

POMEROY, V. et al. Neurological principles and rehabilitation of action disorders: rehabilitation interventions. Neurorehabilitation and Neural Repair, v. 25, n. 5, p. 33-43, 2011. Suplemento.

PROCHASKA, J. O.; DICLEMENTE, C. C. The transtheoretical approach. In: NORCROSS, J.; GOLDFRIELD, M. R. (Org.). Handbook of psychotherapy integration. New York: Oxford University Press, 2005. p. 147-171.

RIBEIRO, T. C. Os jogos digitais na fisioterapia do doente vítima de Acidente Vascular Cerebral. 2016. Dissertação (Mestrado em Comunicação Multimédia) - Departamento de Comunicação e Arte, Universidade de Aveiro, Aveiro, Portugal, 2016.

RIBEIRO, T. C.; VELOSO, A. I.; COSTA, R. Conceptualization of PhysioFun Game: A low-cost videogame for home-based stroke rehabilitation. In: INTERNATIONAL CONFERENCE ON TECHNOLOGY AND INNOVATION IN SPORTS, HEALTH AND WELLBEING, 1., 2016, Vila Real. Anais... Vila Real, 2016.

RICE, M. et al. Evaluating gesture-based games with older adults on a large screen display. In: ACM SIGGRAPH SYMPOSIUM ON VIDEO GAMES, 2011, Vancouver. Anais... New York: ACM, 2011. p. 17-24.

SACCO, R. L. et al. An updated definition of stroke for the 21 st century: a statement for healthcare professionals 
from the American Heart Association/American Stroke Association. Stroke: a Journal of Cerebral Circulation, v. 44, n. 7, p. 2064-2089, 2013.

SAFFER, D. Designing gestural interfaces: touchscreens and interactive devices. Sebastopol, Califórnia: O'Reilly Media, 2008.

SALEN, K.; ZIMMERMAN, E. Rules of play: game design fundamentals. Massachusetts: MIT press, 2004.

SCHULER, D.; NAMIOKA, A. Participatory design: Principles and practices. New Jersey: Lawrence Erlbaum Associates Publishers, 1993.

SWORD HEALTH. Physical terapy made digital. 2016. Disponível em: $<$ http://swordhealth.com>. Acesso em: 30 jun. 2016.

TRUELSEN, T.; EKMAN, M.; BOYSEN, G. Cost of stroke in Europe. European Journal of Neurology, v. 12, p. 78-84, 2005. Suplemento 1.

UN MILLENIUM PROJECT. Investing in development a practical plan to achieve the Millenium Development Goals. United Nations Development Programme Report to the UN Secretary-General. New York: United Nations Development Programme, 2005.

VAN DEN AKKER, J. et al. (Ed.). Design approaches and tools in education and training. [S.1]: Springer Science Business Media Dordrecht, 1999.

VEERBEEK, J. M. et al. What is the evidence for physical therapy poststroke? A systematic review and meta-analysis. PloS One, v. 9, n. 2, 2014. Disponível em: <http://www.ncbi.nlm.nih.gov/pmc/articles/PMC3913786/>. Acesso em: 25 jul. 2016.

VELOSO, A. I. (Coord.) SEDUCE - utilização da comunicação e da informação em ecologias web pelo cidadão sénior. Porto: Afrontamento, 2014.

WARD, N. S. et al. Motor system activation after subcortical stroke depends on corticospinal system integrity. Brain : A Journal of Neurology, v. 129, n. 3, p. 809-819, 2006.

YONG JOO, L. et al. A feasibility study using interactive commercial off-the-shelf computer gaming in upper limb rehabilitation in patients after stroke. Journal of Rehabilitation Medicine, v. 42, n. 5, p. 437-441, 2010.

ZAVALA-IBARRA, I.; FAVELA, J. Ambient videogames for health monitoring in older adults. In: INTERNATIONAL CONFERENCE ON INTELLIGENT ENVIRONMENTS, 8., Guanajuato, México, 2012. Anais... IEEE, 2012. p. 27-33.

ZWARTRUIS-PELGRIM, E.; RUYTER, B.. Developing an adaptive memory game for seniors. MARKOPOULUS, P. el al (Ed.). Fun and games. Berlin: Springer Verlag Berlin Heidelberg, 2008. p. 170-181.

Recebido em: 06.04.2016

Aprovado em: 25.07.2016 